\title{
Evolution of Geographic Atrophy of the Retinal Pigment Epithelium
}

\author{
J. P. SARKS ${ }^{1}$, S. H. SARKS ${ }^{2}$ and M. C. KILLINGSWORTH ${ }^{2}$ \\ Sydney, Australia
}

\section{Summary:}

The aim of this study was to trace the evolution of geographic atrophy (GA) by clinical documentation and by clinico-morphological correlation in representative eyes. Geographic atrophy commonly commenced within a parafoveal band of incipient atrophy of varying width, characterised by semisolid drusen and a microreticular pigment pattern. Progession of atrophy mostly skirted fixation and visual acuity was a poor guide to the functional impact, an estimate of the percentage of fovea involved proving a more useful clinical parameter. The rate of progression slowed once GA had involved all the retina affected by incipient atrophy and the risk of choroidal neovascularization appeared to decline.

An earlier histological classification of the evolution of GA is revised according to the ultrastructural findings. Membranous debris was not previously recognised and its contribution to the findings in incipient atrophy and to dot-like drusen is described.

Geographic atrophy (GA) of the retinal pigment epithelium (RPE) is the outcome of the atrophic form of age-related macular degeneration (AMD). The term was applied by Gass $^{1}$ to one or more circumscribed areas of atrophy which slowly enlarge and coalesce such that the spreading lesion is often irregular. In time the outline tends to become rounded, hence Green and Key ${ }^{2}$ proposed the term areolar. Affected areas have no visual function since loss of the RPE is associated with fallout of photoreceptors as well as a variable degree of choroidal atrophy.

GA is acknowledged to be a less common form of AMD than a neovascular maculopathy, accounting for only $12-21 \%$ of legally blind eyes. ${ }^{3,4}$ However, such patients may not be referred to a retinal centre and in a fixed elderly population the prevalence of the advanced condition appears to be higher. ${ }^{5}$
Furthermore, even large areas of atrophy may spare fixation and consequently visual acuity does not reflect the functional handicap. There are no satisfactory parameters with respect to the size of the lesion or its effect upon vision.

The aim of this study was to trace the evolution of GA by clinical documentation and by clinico-morphological correlation in representative eyes. An earlier histological classification ${ }^{5}$ of the stages preceding atrophy is revised according to the ultrastructural findings.

\section{Material and Methods}

Two hundred and eight patients, 79 males and 129 females whose average age was 75.6 years (range 51-94 years), either presented with or were observed to develop GA in one or both eyes. GA was defined as one or more circumscribed areas of pigment epithelial loss 
in which fluorescein angiography demonstrated a transmission defect. This appeared in the early phase, did not alter in size or shape and showed late staining due to spread of dye from adjacent choroidal capillaries.

GA was distinguished from areas of pigment epithelial attenuation ${ }^{6}$ which were less sharply defined, pinker areas of the fundus. Such areas demonstrated less intense and more diffuse hyperfluorescence (Fig. 1) in which pigment clumping sometimes formed a microreticular pattern (Fig.3.) Any typical drusen present showed signs of fading but small dot-like drusen were often noted. Vision was not as severely affected and this appearance was referred to as incipient atrophy.

Using the planimetric method to be described, at least one of the areas of atrophy had also to meet the following conditions (Figs 1,2):

(1) Encroachment into the fovea. Atrophy occasionally reached a large size without entering the fovea, but such eyes were ignored since the functional implications of GA related more closely to foveal involvement.

(2) Atrophy measuring at least $1.0 \mathrm{~mm}$ in one dimension. This was larger than the focal patch of atrophy left by the fading of most drusen and implied spread into the surrounding RPE.

Eyes showing clinical evidence of prior choroidal neovascularisation were not considered, even when atrophy was the predominant change. Eyes were also excluded where atrophy was known to be secondary to other degenerations such as myopia or angioid streaks, known rips of the RPE, dystrophies, adult vitelliform lesions and inflammatory or toxic diseases affecting the RPE. Finally, patients were only included if fundus photography was possible, using a Zeiss (Oberkochen) fundus camera. All but 31 patients also had fluorescein angiography.

\section{Recording of Data.}

The procedure used to measure the area of atrophy was based on the method used in the Macular Photocoagulation Study ${ }^{7}$ to record neovascular membranes. Colour and fluores-

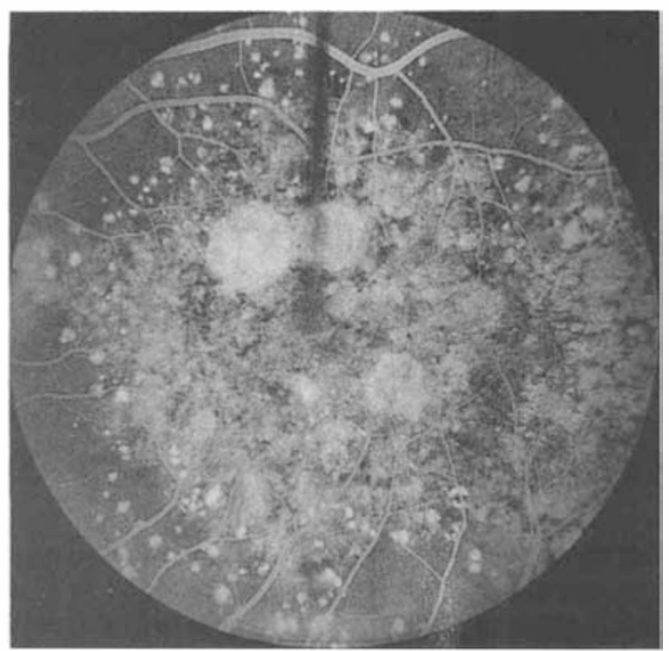

Fig. 1. Fluorescein angiogram of a 49-year-old man showing development of drusen-related atrophy of the RPE. Rounded patches of $G A$ are sharply defined and brightly hyperfluorescent, in contrast to the less intense, more diffuse hyperfluorescence present throughout the central area. GA enlarges into retina first affected by this incipient atrophy. Vision remained 6/5.

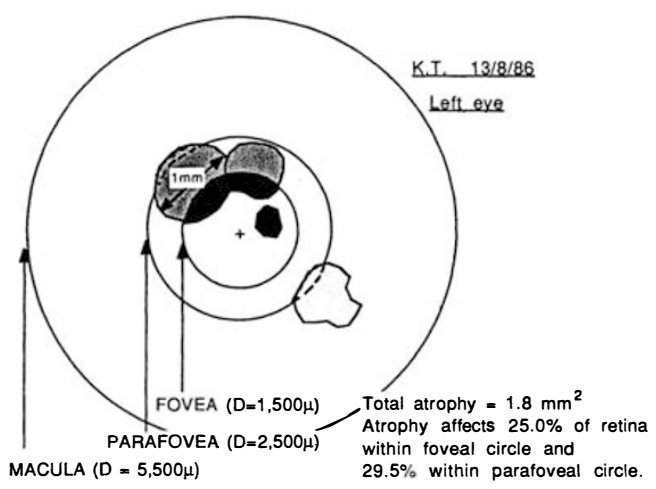

Fig. 2. Drawing of eye illustrated in Fig 1, obtained by tracing over fluorescein angiogram slide projected onto a digitising pad. The largest patch of atrophy measures $1.0 \mathrm{~mm}$ in one dimension and atrophy enters the fovea, qualifying this patient for inclusion in survey. Automatic area display permits calculation of percentage of retina affected within foveal and parafoveal circles. The four areas shown are included in the calculations but patches of atrophy measuring less than $0.3 \mathrm{~mm}$ in Fig 1 are ignored. Parafoveal involvement refers to all retina inside this circle and therefore includes fovea. 
cein angiography slides with the Zeiss camera in an emmetropic eye provided a retinal magnification of three times. A frame of the fluorescein angiogram was projected by means of a Zeiss Dokumator DL2 Microfilm Reader at $6.5 x$ magnification directly onto a digitising pad, permitting a 1:1 reproduction between the pad and the computer screen.

The slide was positioned such that the centre of the fovea corresponded as closely as possible to the centre of three concentric circles representing the fovea (diameter 1.5 $\mathrm{mm}$ ), parafovea (diameter $2.5 \mathrm{~mm}$ ) and the central area or macula (diameter $5.5 \mathrm{~mm}$ ) (Fig.2). Using a program with an automatic area display, the outlines of all areas were traced with a stylus. Although an eye was not admitted into the survey until one area of atrophy measured $1 \mathrm{~mm}$ across, smaller areas were nevertheless included in the calculations. Those smaller than $0.3 \mathrm{~mm}$, however, proved impractical to measure and were ignored.

The total atrophy was expressed in square millimetres and the percentage of involved retina within the foveal and parafoveal circles was calculated. Patients were grouped into those with the earliest $(<10 \%)$ foveal involvement and then into progressive thirds, since these categories could readily be estimated clinically. The main difficulty was determining the centre of the fovea on the photographs when fixation was unsteady or eccentric. At times it could only be estimated within a radius of $1 / 5 \mathrm{DD}(300 \mu)$ and this could have affected the measurement of foveal involvement by as much as $20 \%$. Parafoveal involvement referred to all the retina affected within this circle, including that within the fovea. Atrophy outside the central area was ignored.

If both eyes suffered from GA, the eye designated as the survey eye was the one with the greater percentage of foveal involvement. The state of the macula in the fellow eye was then placed into one of four categories:

-AMD which had not yet developed GA -a lesser degree of GA

-choroidal neovascularisation. Note was made of when this had occurred. -other diagnosis.

\section{Observation.}

Photographic documentation prior to the onset of atrophy was available on 42 patients, the average period of observation before inclusion in the survey being 64.6 months. Subsequent progress of the atrophy was documented in 61 patients followed for an average period of 29 months.

\section{Clinicopathological examination.}

Five eyes from five patients regarded as representative of the clinical findings are reported in this study. The eyes were prepared for electron microscopy using techniques previously described. ${ }^{8}$

\section{Results}

Three patterns of evolution were distinguished (Table I). The great majority of patients fell into the first two groups in which GA was preceded by incipient atrophy and usually commenced around the foveal perimeter.

(1) Primary age-related atrophy. In these patients drusen did not appear to determine the pattern of atrophy.

(2) Drusen-related atrophy. This group typically displayed small, discrete, rounded patches of atrophy in relation to individual regressing drusen or drusen clusters. Gradually this multifocal pattern became confluent and the drusen faded, but their earlier influence could be inferred from residual calcified particles and from surrounding patches of drusen-related atrophy. In a small subgroup of younger patients the drusen were so densely packed that focal patches of GA developed without obvious relationship to individual drusen (Fig.1).

(3) Other causes. In nine patients GA followed some other manifestation of AMD, usually the resolution of a serous retinal pigment epithelial detachment and especially those detachments formed by the confluence of soft drusen as described by Bird and Marshall. ${ }^{9}$ Vision remained satisfactory for many years until the RPE over the detachment failed. It then deteriorated rapidly, the detachment flattened and a corresponding area of atrophy rapidly followed.

In middle age one or several pigment clumps were not uncommonly found close to 
Table I. Classification of 208 patients with geographic atrophy in survey eye

\begin{tabular}{lrc}
\hline Group & Number & $\begin{array}{c}\text { Average age } \\
\text { (years) }\end{array}$ \\
\hline $\begin{array}{l}\text { 1. Primary age-related } \\
\quad \text { atrophy }\end{array}$ & 77 & 78.4 \\
2. Drusen-related atrophy & & \\
a) Multifocal & 114 & 75.2 \\
b) Generalised & 8 & 63.6 \\
3. Other lesions & 9 & 68.2 \\
$\quad \quad$ Total & 208 & 75.6 \\
\hline
\end{tabular}

fixation, occasionally with underlying yellowish material resembling adult vitelliform dystrophy and as these slowly faded over many years, small patches of atrophy remained. ${ }^{10}$ This third group was thought to have a different pathogenesis and is not described further.

1. Primary age-related geographic atrophy.

Commonly the atrophy commenced in relation to a microreticular pigment pattern lying in a band of incipient atrophy around the perimeter of the fovea. Fluorescein angiography demonstrated that the atrophy was preceded by an irregular mottled window defect adjacent to lines of hyperpigmentation or around individual pigment clumps (Fig.3). Small dot-like drusen $25 \mu-50 \mu$ in size were often noted in the surrounding incipient atrophy and were more easily seen in redfree light. On fluorescein angiography they appeared as brighter dots in the diffusely hyperfluorescent background (Fig.6).

Spread continued into retina affected by incipient atrophy, expanding in a pincer-like fashion around the central fovea or developing simultaneously in several parts of the parafovea (Figs 4,5). The patches enlarged more rapidly when the ring of pigment clumps was pronounced. The nasal or temporal sides of this encirclement were usually the last to close, completing the bull's-eye which spared fixation such that patients often retained a good visual acuity for many years (Fig.6). Visual acuity dropped more rapidly when the centre of the fovea also showed pigmentary mottling, but often the centre remained remarkably resistant even when atrophy reached a large size. When GA had involved all the retina displaying incipient atrophy its progress slowed.

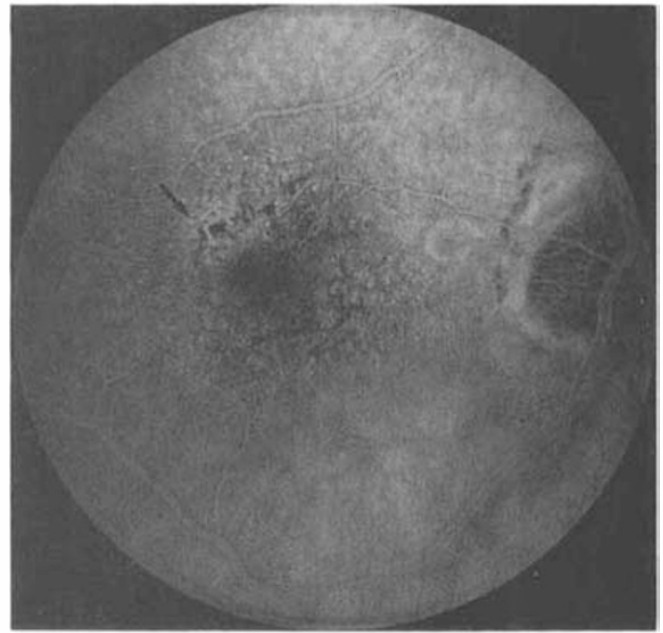

Fig. 3. Figures 3-6 illustrate the development of primary age-related $G A$. Fluorescein angiogram is of right eye of a 74-yr-old woman with a microreticular pattern of pigment clumps and lines around the perimeter of the fovea and adjacent to disc. Hyperfluorescence appears around pigment clumps in the upper temporal quadrant (arrow). Small hyperfluorescent dots are distributed around the fovea. Vision was 6/6. The other eye had lost central vision a year earlier as a result of disciform degeneration.

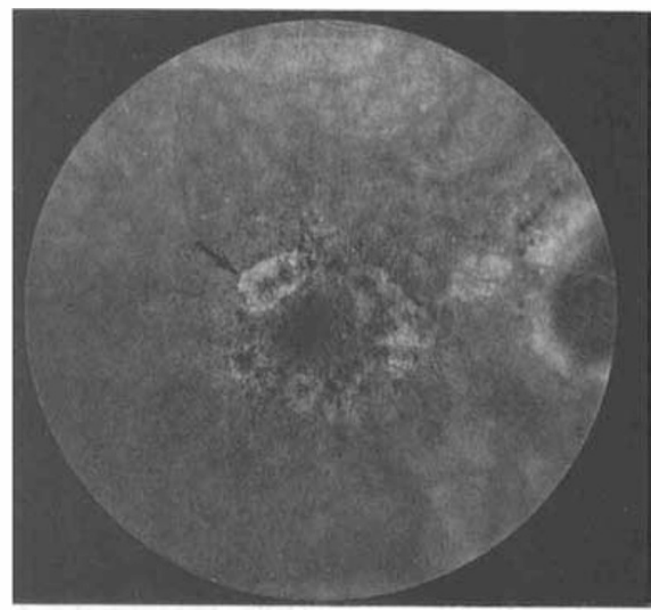

Fig. 4. One year later small patches of atrophy had developed around the pigment clumps. The largest, $1 \mathrm{~mm}$ long, was located where hyperfluorescence had commenced (arrow). 
Three clinicopathological reports of primary GA are presented. In the first case GA was of recent onset and the morphological changes were traced from areas of moderate and then severe degeneration, to the junctional zone at the edge and then into the area of atrophy. In case 2 (medium duration) and case 3 (long duration) the observations were limited to the junctional zone.

Case 1 (Fig.7) was a patient followed for six years before death at the age of 83 . Both eyes had been

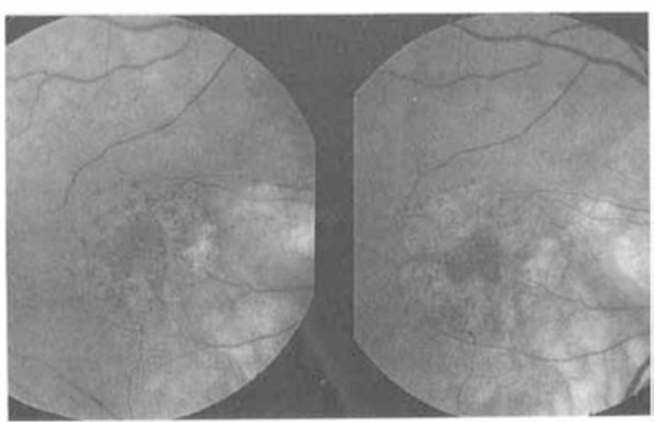

Fig. 5. Showing enlargement and coalescence of atrophy into an almost complete ring around the fovea. Involvement of the parafovea remained in advance of the fovea. At age 76 (left) atrophy measured $2.8 \mathrm{~mm}^{2}$, occupied $30 \%$ of the fovea and $50 \%$ of the parafovea. At 77 (right) the area had almost doubled to $5.0 \mathrm{~mm}^{2}$, occupied $60 \%$ of the fovea and $90 \%$ of the parafovea. Vision was still $6 / 6 \mathrm{p}$ but the patient experienced difficulty reading.

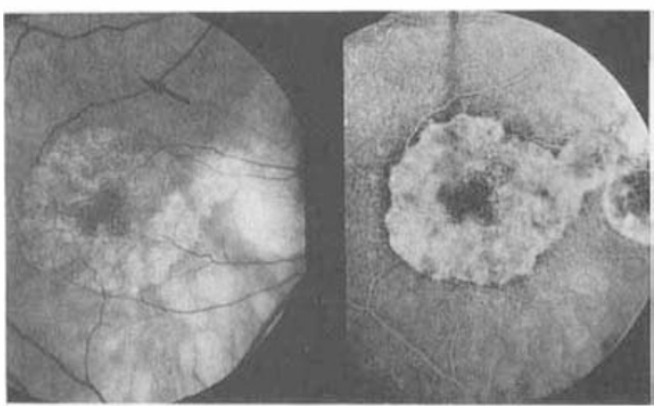

Fig. 6. Red-free photograph (left) and fluorescein angiogram (right), showing appearance at age 79. The bull's-eye pattern was complete, sparing fixation. Note background of small drusen (arrow), corresponding to hyperfluorescent dots. When last seen at age 81 vision was still $6 / 9 \mathrm{p}$. The eye with $G A$ therefore retained central vision eight years longer than the fellow eye with choroidal neovascularisation. observed to develop a fine pigmentary disturbance culminating in a patch of atrophy involving fixation and reducing vision to 3/60. Dot-like drusen were present but did not appear to determine the pattern of atrophy. Both eyes showed similar ultrastructural findings but the left eye retained better postmortem preservation and is illustrated in Figures 8-12.

Zone of moderate degeneration (Fig.8).

The retinal pigment cells were irregular in shape, some being enlarged and others attenuated. They were densely packed with discrete pigment granules, mainly lipofuscin and melanolipofuscin. Hyalinisation and densification of Bruch's membrane extended down the intercapillary pillars to the level of the outer surface of the choriocapillaris.

Several layers of coiled membrane lay between the RPE and its basement membrane, apparently extruded from the basal surface of the RPE which had lost its infoldings. This membranous debris extended inwards between adjacent RPE cells as small rounded mounds generally less than $25 \mu$ wide (Fig.9). A thin stratum of membranes also lay external to the basement membrane.

In addition, abnormal basement membrane material referred to as the basal laminar deposit (BLD) extended inwards from the basement membrane in a bush-like pattern (Fig.8). It was mostly homogeneous but also contained segment longspacing collagen.

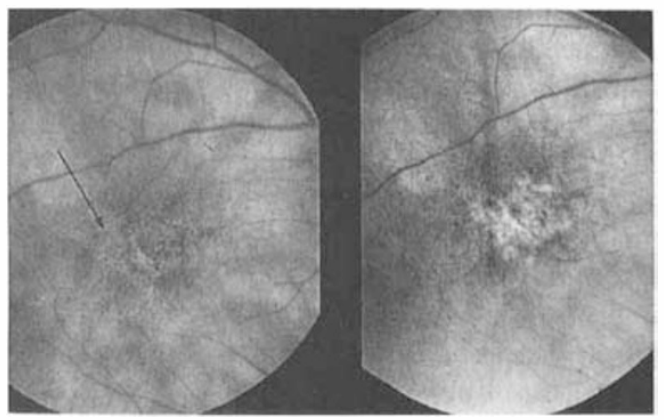

Fig. 7. Right eye of a patient photographed at age 81 and 82. Both eyes had earlier been observed to develop a fine pigmentary disturbance associated with dot-like drusen (arrow, left), culminating in a patch of atrophy involving fixation and reducing vision to 3/60 (right). Patient died four months after this photograph. The ultrastructural findings were similar in both eyes. Figures 8-12 illustrate the findings in the better preserved left eye. 


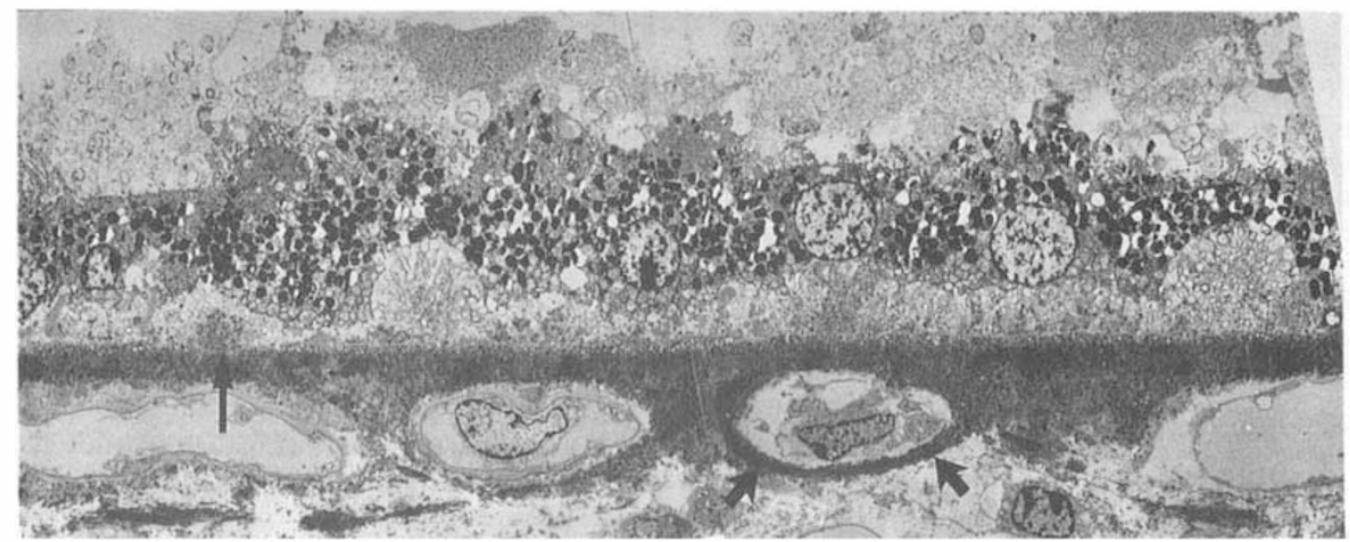

Fig. 8. Electron micrograph from left eye of same patient, about half a disc diameter from junctional zone. Rounded mounds of membranes lie between RPE plasma membrane and basement membrane. Early type BLD (arrow, left) extends inwards from basement membrane in bush-like pattern. Densification of Bruch's membrane extends down intercapillary pillars and surrounds an obliterated choroidal capillary (short arrows). $x 2,240$

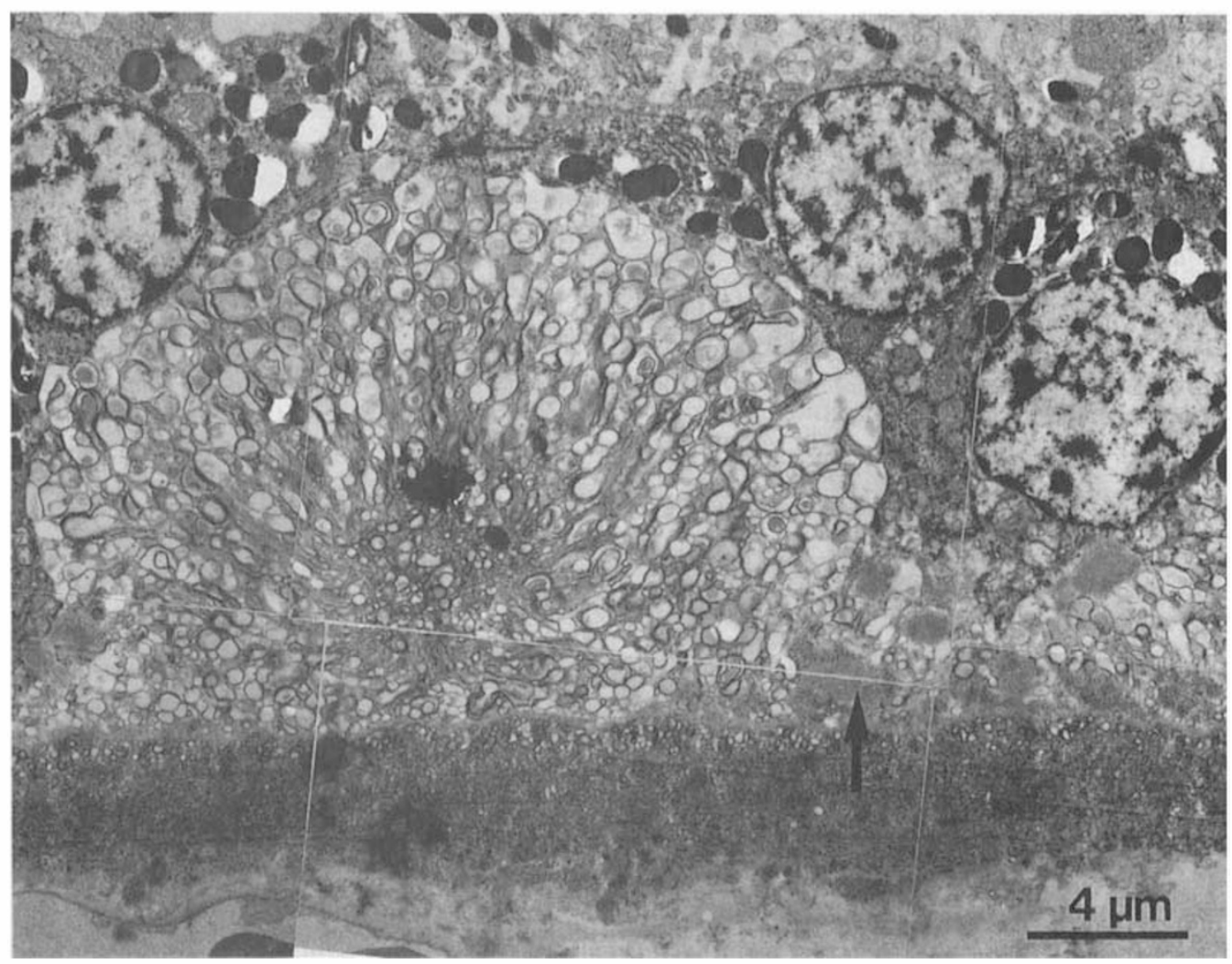

Fig. 9. Higher magnification of a mound. It consists of coiled membranes that appear to be extruded from base of RPE, cells of which have lost basal infoldings. Rounded shape is due to adjacent RPE cells remaining anchored to Bruch's membrane by early type BLD (arrow). These mounds may correspond to dot-like drusen. $x 6,300$ 
Zone of severe degeneration (Fig.10).

Closer to the area of atrophy the mounds of membranous debris had fused. These confluent mounds retained rounded borders, the largest measuring $70 \mu$ wide and $25 \mu$ tall. A few clusters of pigment granules were interspersed among the membrane fragments. The membranes also passed through the basement membrane to separate it from the inner collagenous layer but without forming typical drusen. A small number could even be traced into Bruch's membrane.

The accumulating lipofuscin granules in the RPE had now become aggregated into clumps. The cells became increasingly abnormal in shape and cell fallout was more evident. Lipoidal degeneration was occasionally observed but more of ten a degenerate cell or part of a cell packed with pigment granules was shed into the subretinal space, initially retaining tight junctions to the underlying RPE. The displacement of the cell borders often caused the junctional complexes to become orientated horizontally, the distorted actin microfilaments then becoming compressed into stress fibres (Fig.10). Although these cells in the subretinal space have been

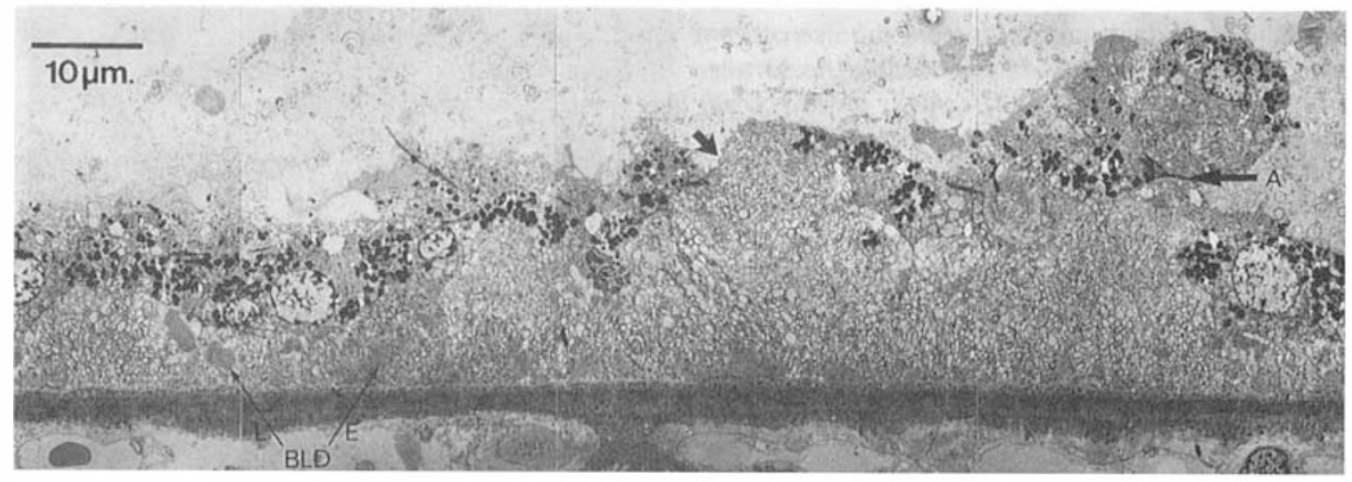

Fig. 10. Section closer to junctional zone, showing a confluent mound $70 \mu$ wide. The RPE is extremely attenuated and short arrow points to possible communication between membranes and subretinal space. At upper right a degenerate cell appears to be ejected into the subretinal space but is still attached to RPE by tight junctions. Distortion of cell borders compresses actin microfilaments into stress fibres (A). BLD lies at different levels, early bush-like form $(E)$ arising from the basement membrane while later flocculent type (L) is raised over membranes. Note only a minimal amount of membranous debris lies external to basement membrane. $x 2,240$

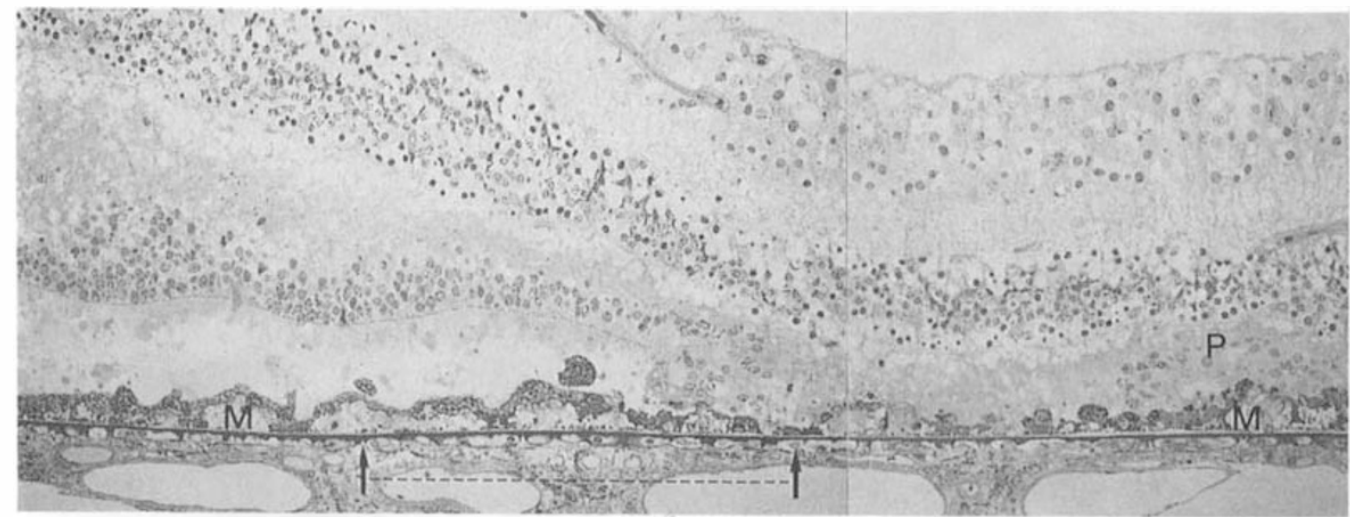

Fig. 11. Semi-thin plastic section passing through junctional zone showing termination of RPE which is shedding cells into subretinal space. Mounds of pale-staining material $(M)$ lie beneath RPE where photoreceptors are still present. Another mound is found in the area of atrophy at right where a whorl of surviving photoreceptors $(P)$ is related to a few degenerating retinal pigmentcells. The zone between the arrows is magnified in Fig 12. Methylene blue and basic fuchsin. x205 


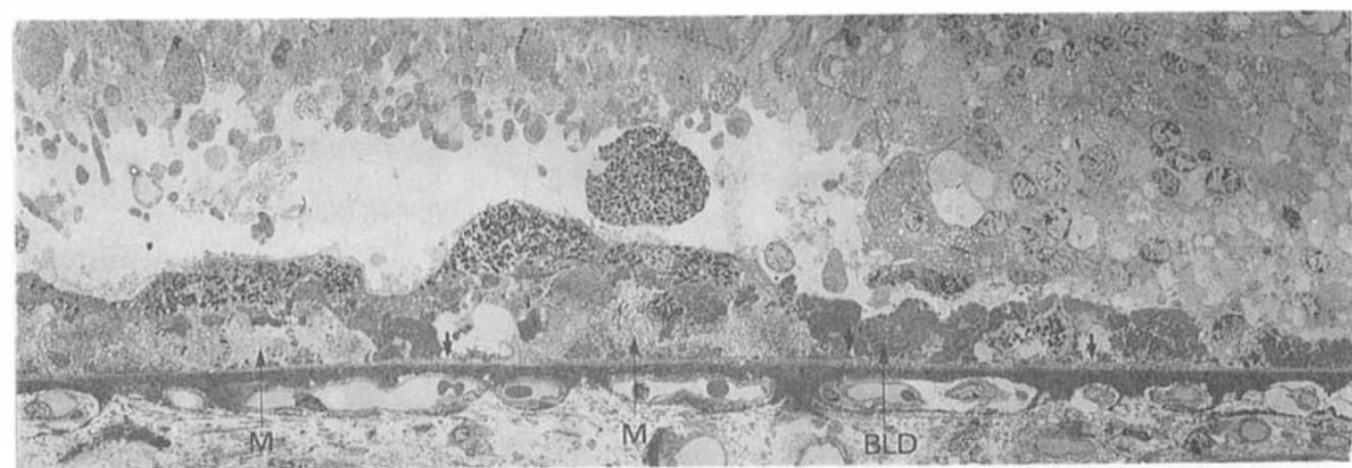

Fig. 12. Electron micrograph of the junctional zone shown in Fig 11. The photoreceptor inner segments are stunted and widened, the outer segments disorganised. Hyperpigmented degenerated RPE cells and cell fragments lie in subretinal space and also beneath RPE. The mounds $(M)$ consist of membranes and cease where the photoreceptors disappear. Flocculent BLD related to the base of the RPE lies between and over the membrane mounds and is continued into the area of atrophy at right. Both membranes and BLD lie internal to the RPE basement membrane (short arrows). A thin layer of membranes also lies external to basement membrane. The choriocapillaris narrows in the area of atrophy at right. $x 720$

referred to as macrophages, the presence of tight junctions, abundant smooth endoplasmic reticulum, a few distorted apical villi or associated basal laminar material confirmed their RPE derivation.

As the RPE became increasingly disorganised another form of BLD appeared, although better developed in eyes with longstanding atrophy (Figs. 12,21). It consisted mainly of amorphous clumps but in parts it appeared fibrillar and also contained longspacing collagen. It usually remained closely applied to the base of the RPE and thus also became separated from the basement membrane by the membranous debris. This later form of BLD therefore lay at different levels which gave it a flocculent, multilaminar or cumuliform appearance. Being a later development than the bush-like BLD, it formed a distinct layer on the internal surface of the earlier form.

\section{Junctional zone (Figs.11,12).}

Closer to the edge there was no evidence of phagocytosis and the few surviving photoreceptors were grossly abnormal. The inner segments appeared shortened and bulbous, while the outer segments were fragmented. The photoreceptors and RPE then disappeared together, the external limiting membrane ending in a curved line. At the same time the membranous debris reduced in amount, the outline of the earlier membrane mounds remaining as small apparently empty spaces under the flocculent BLD as the latter continued into the area of atrophy.

At these junctional zones large hyperpigmented RPE cells were being shed into the subretinal space (Fig.12). Many contained large membrane-bound bodies filled with fused lipofuscin and melanolipofuscin granules embedded in a grey matrix. These intracytoplasmic structures may have been derived by autophagy or from neighbouring cells that had been deleted or the result of autophagy. The remaining condensed cytoplasm contained few organelles and only an occasional abnormal nucleus.

Pigment-laden cells and giant cells were also found on Bruch's membrane under the basement membrane of the RPE. This was especially evident in the junctional zone where presumably the greatest amount of debris had to be removed.

The area of atrophy.

In the area of atrophy an occasional whorl of persisting photoreceptors converged on a cluster of degenerating pigment cells (Fig.11). Elsewhere the photoreceptors had disappeared but a few grossly abnormal retinal pigment cells or membrane-bound bodies containing pigment commonly remained scattered throughout the area. The BLD, 
especially the later flocculent form, could generally be traced throughout the area of atrophy. The outer nuclear layer disappeared and an attenuated outer plexiform layer rested directly on the $B L D$, but the inner nuclear layer was less affected.

\section{Case 2}

Figs.13 and 14 illustrate a patient documented over 17 years. Despite the fact that the pigment changes commenced closer to fixation he retained good vision for many years. GA spread into the surrounding incipient atrophy (Fig.15) and by the time of death progress of the atrophy had slowed. GA in this patient was therefore of longer duration than in Case 1.

The junctional zone in this eye (Fig.16) showed certain differences from Case 1. More hyperpigmented cells were being shed into the subretinal space, accounting for the dark border noted clinically. In the area of atrophy there were fewer surviving retinal pigment cells and photoreceptors. Choroidal atrophy was more advanced.

The giant cells and pigment-laden cells found on Bruch's membrane in the junctional zone in Case 1 were more difficult to find. Membranous debris was also less evident under the RPE. However, for some distance around the atrophy the photoreceptor outer segments terminated in rounded collections of membranes lying on the internal surface of the RPE, each partly surrounded by broad apical extensions from the cells (Figs.17,18). There was little evidence of phagocytosis.

\section{Case 3}

This patient was a 91-year-old woman demonstrating long-standing geographic atrophy associated with choroidal atrophy (Fig.19). In this eye the termination of the RPE was again characterised by a double layer of cells (Fig.20). The outer layer comprised umbrella-shaped hyperpigmented cells

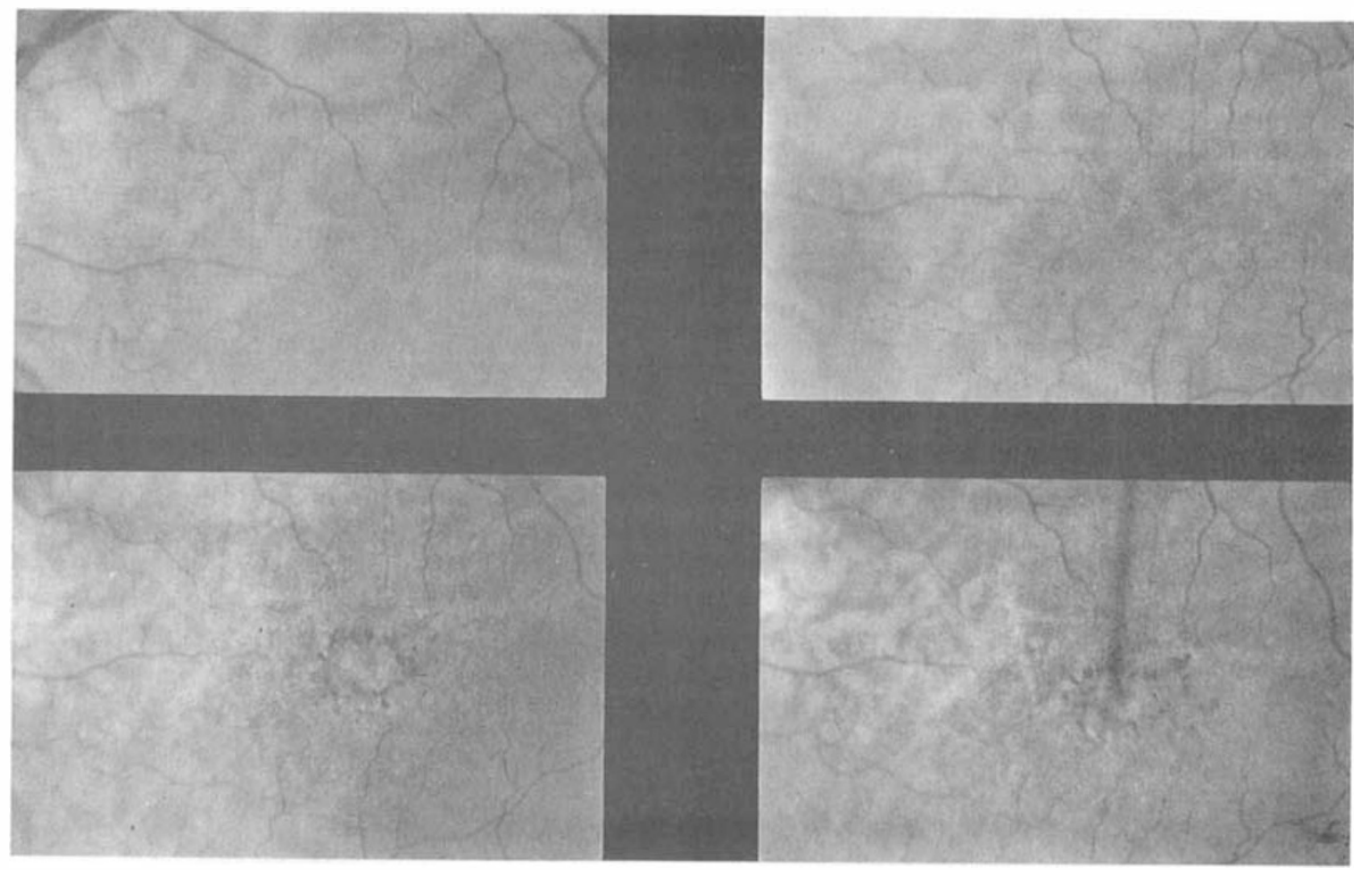

Fig. 13. Another patient documented over 17 years, illustrating evoution of primary age-related atrophy. Top left: Age 68, normal left fundus with senile tigroid pattern. Vision 6/5. Top right: Age 73, dot-like drusen faintly visible. Vision 6/6. Lower left: Age 77, pigmentary disturbance developing around the centre of the fovea. Dot-like drusen more apparent. Lower right: Age 79, ring of pigment clumps surrounds fixation, vision still 6/6. Choroidal vascular pattern more prominent. 


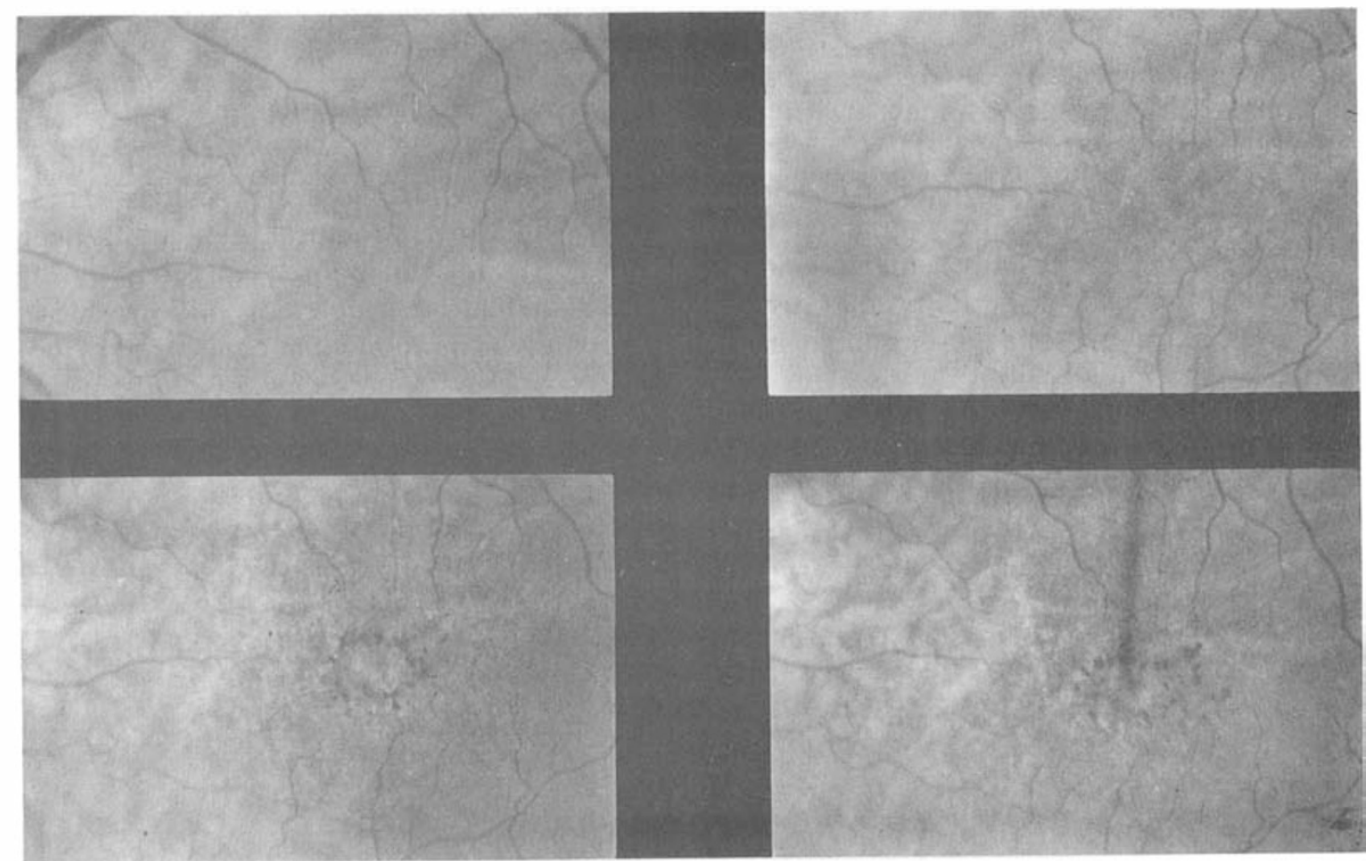

Fig. 14. Top left and right (red free): Age 81. Patches of atrophy had developed, not large enough for inclusion in the survey. Pigment clumping and small dots are spreading into remainder of fovea. Arrow indicates faint outline of incipient atrophy, confirmed on fluorescein angiogram (Fig. 15). Vision still 6/9p. Lower left: Age 82 when patient was included in survey. Atrophy now $2.3 \mathrm{~mm}^{2}$ in area. Fixation affected, vision 6/60. Lower right: Age 84. Atrophy almost doubled in area $\left(4.3 \mathrm{~mm}^{2}\right)$, vision 3/60. Note upper hyperpigmented edge. Choroidal atrophy causes exposed vessels to appear white. Patient died aged 85.

while the innermost cells were filled with residual bodies and appeared to be necrotic cells in the process of elimination. The overlying photoreceptors had largely disappeared for some distance beyond the edge and there was a corresponding reduction in the amount of membranous debris, but flocculent BLD was prominent (Fig. 21).

From examination of these and other eyes with geographic atrophy, the loss of the RPE and photoreceptors occurred in advance of the loss of the choriocapillaris. The capillaries gradually lost their fenestrations and became surrounded by fibroblast processes and collagen, retracting from Bruch's membrane and also becoming more widely spaced.

In cases 2 and 3 choroidal atrophy caused the exposed choroidal arteries to display white sheathing of their walls or appear bloodless (Figs. 14,19). The appearance seemed to be due principally to loss of the choriocapillaris and middle layer of the choroid, thereby throwing the remaining larger vessels into greater prominence. Other factors which may have contributed to the picture were the flattening of the vessel walls in the thinned choroid and a reduction in the width of the blood column. The majority of arteries showed only fibrous replacement of the media without thickening of their walls and with the retention of wide lumina (Figs. $16,2(0)$.

\section{Drusen-related atrophy.}

Degeneration of the RPE occurred preferentially over drusen. A small subgroup of patients in whom drusen were especially numerous represented the youngest in this series. one patient developing $\mathrm{GA}$ at age 51 years and losing fixation in the first eye at 54 years but currently retaining it in the second eye at 57 years. The youngest to lose fixation in both eyes to date was aged 66 . 


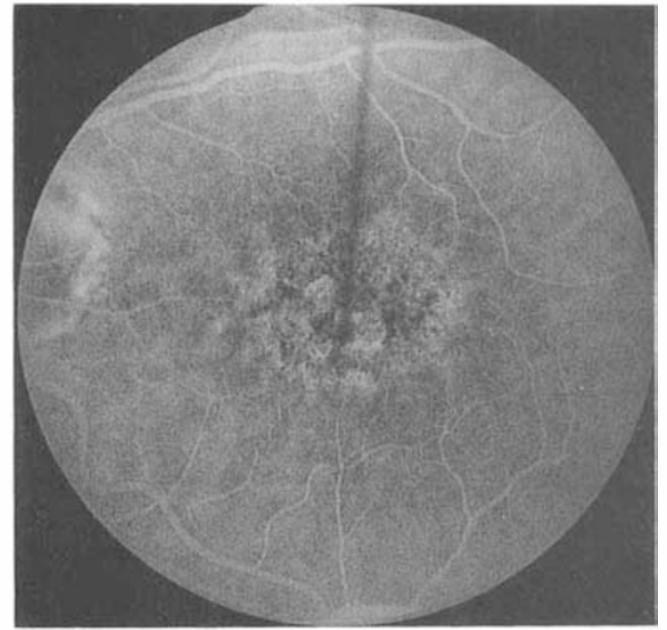

Fig. 15. Fluorescein angiogram of previous patient at age 81, corresponding to Fig 14, top. Small patches of $G A$ are outlined centrally, surrounding retina demonstrates pigment clumping and diffuse hyperfluorescence. This incipient atrophy corresponds to subsequent area of $G A$ (Fig. 14, lower right).

\section{Semisolid drusen}

In this series drusen-related atrophy was most often noted in relation to clusters of hard drusen lying in and around the parafovea. These drusen initially remained discrete (Fig.22) but in time, apparently due to the addition of membranous debris, they aggregated into larger deposits in which the individual small drusen or the broken down particles could often be distinguished in redfree light and on fluorescein angiography. These broken down clusters were referred to as semisolid drusen .

The atrophy commenced in a multifocal pattern but as age-related degeneration affected the intervening retina, the patches enlarged and coalesced. Like primary agerelated atrophy, drusen-related atrophy also tended to spare fixation until the late stages (Fig.23).

\section{Soft drusen}

The softening of hard drusen or the formation of soft drusen de novo appeared to occur

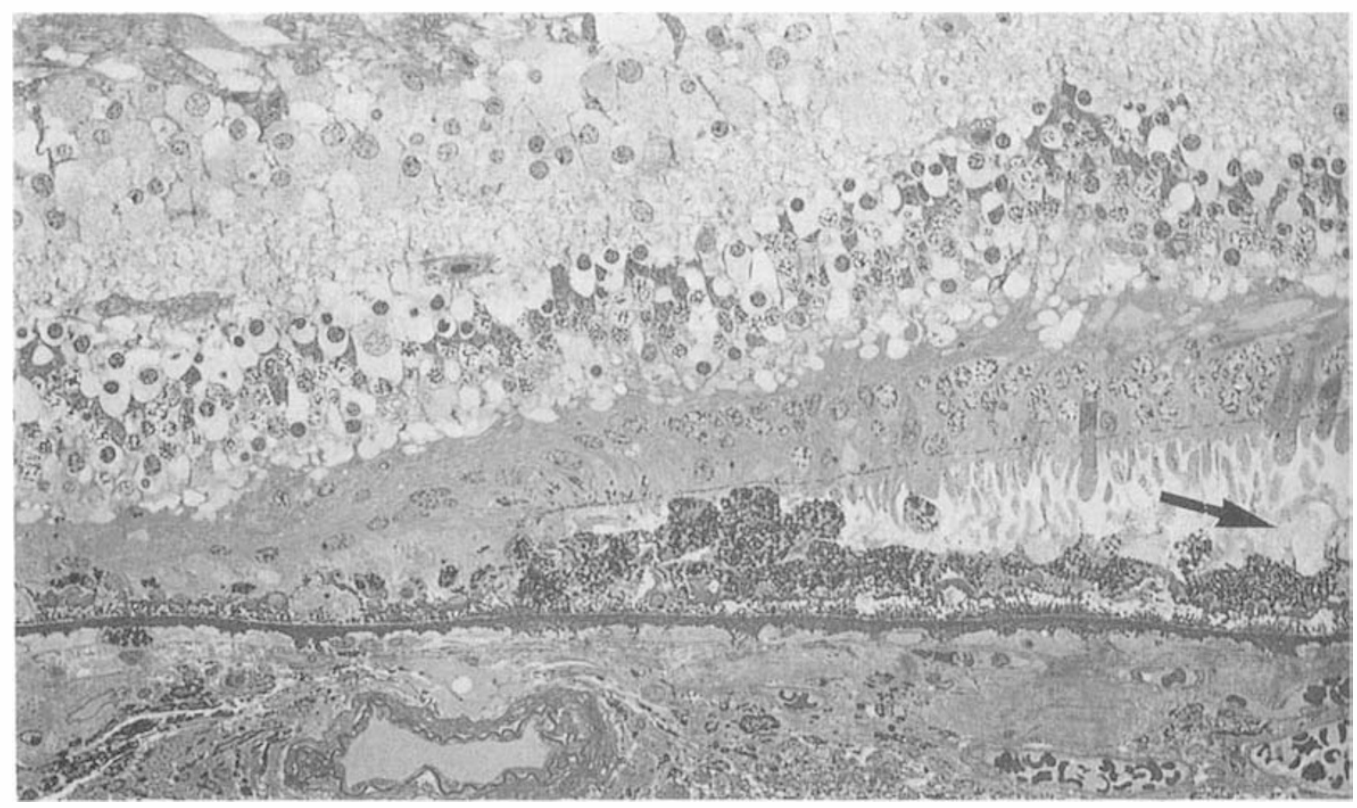

Fig. 16. Semi-thin section through edge of area of atrophy of eye illustrated in Figs. 13-15. The hyperpigmented border noted clinically corresponds to a double layer of RPE, the inner layer representing degenerate hyperpigmented cells in the process of being eliminated. Cone inner segments become wider and stunted before disappearing. Photoreceptor outer segments end in collections of debris (arrow) on internal surface of RPE. Note choroidal artery retains a wide lumen. Methylene blue and basic fuchsin. x320 
when the mounds of membranous debris under the RPE discharged their contents external to the basement membrane. In so far as soft drusen indicated a more advanced stage of degeneration, they evolved and faded more rapidly than other drusen and the most rapidly developing atrophy followed drusen pigment epithelial detachments. Shallow soft drusen occasionally formed a subtle sinuous pattern in the fundus background but the larger soft drusen were usually located within the fovea (Fig. 24), so that atrophy developing in relation to these commenced closer to fixation.

\section{Regressing drusen}

In drusen-related atrophy the drusen were observed to pass through various stages of regression. Clinical indications that a druse was commencing to regress were a whiter and harder appearance and pigment stippling over the surface, changes best seen in redfree light. Figure 25 demonstrates commencing regression of a druse from an eye shown in Figure 24. The RPE was attenuated and a thick layer of flocculent BLD covered the druse, often presenting a series of small nodular elevations. The photoreceptor inner segments were stunted and reduced in number and the outer segments had disappeared. The outer nuclear layer was attenuated and the external limiting membrane bowed inwards.

More advanced regression in a druse from the same eye is illustrated in Figure 26. Only a few RPE cells remained over the flocculent BLD. The outer nuclear layer and photoreceptors were absent, the external limiting membrane moving progressively down the slopes of the druse and defining the limits of atrophy. Loss of RPE was therefore associated with loss of photoreceptors, absence of membranous debris internal to the basement membrane and regression of the drusen.

Regressing drusen showed evidence not only of reduced formation of membranous debris, but also of its removal by mac-

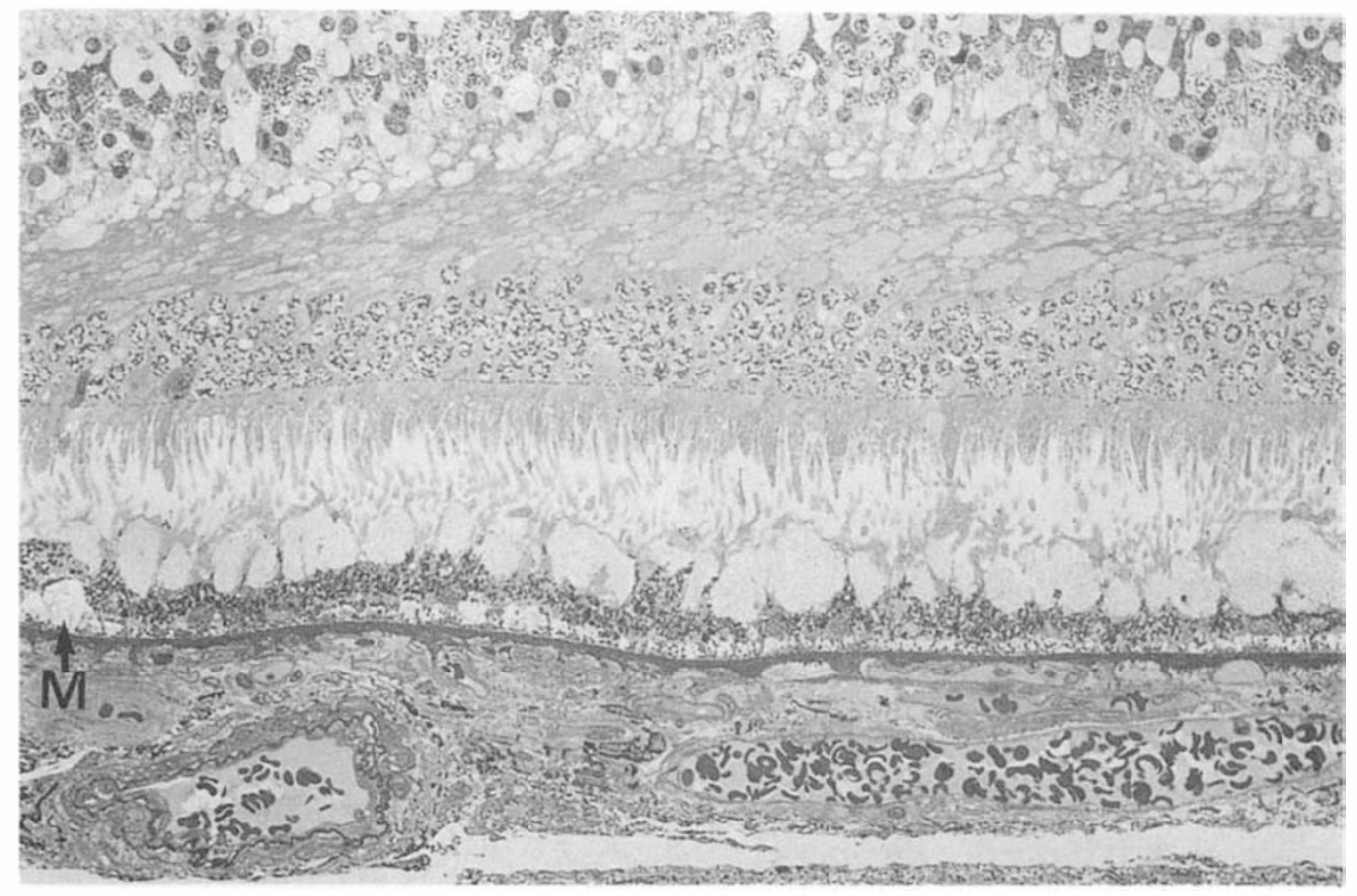

Fig. 17. Semi-thin section slightly further from edge. An array of discrete rounded collections of debris lies on inner surface of the RPE, each partly surrounded by broad apical extensions from the cells. $M=$ mound of debris external to RPE. Methylene blue and basic fuchsin. $x 320$ 
rophages. Material not removed developed calcification or became invaded by collagen fibres or the processes of Müller cells passing through the BLD. Clinically drusen developing these late changes became increasingly irregular and displayed points of calcification, especially after the age of 60 years. Ultimately only glistening particles may be seen.

Figure 28 demonstrates dystrophic calcification in a druse from an eye illustrated in Figure 27 and, although not confirmed by the elegant two-dimensional reconstructions used by Green and $\mathrm{Key}^{2}$, this finding was noted with sufficient frequency to regard it as a clinicopathological correlation. Choroidal neovascularisation was also noted in relation to the regressing druse in this eye but did not progress.

\section{Clinical implications.}

The percentage of fovea involved was the most convenient overall parameter since it related to the visual acuity, the size and progression of the area of atrophy as well as to the

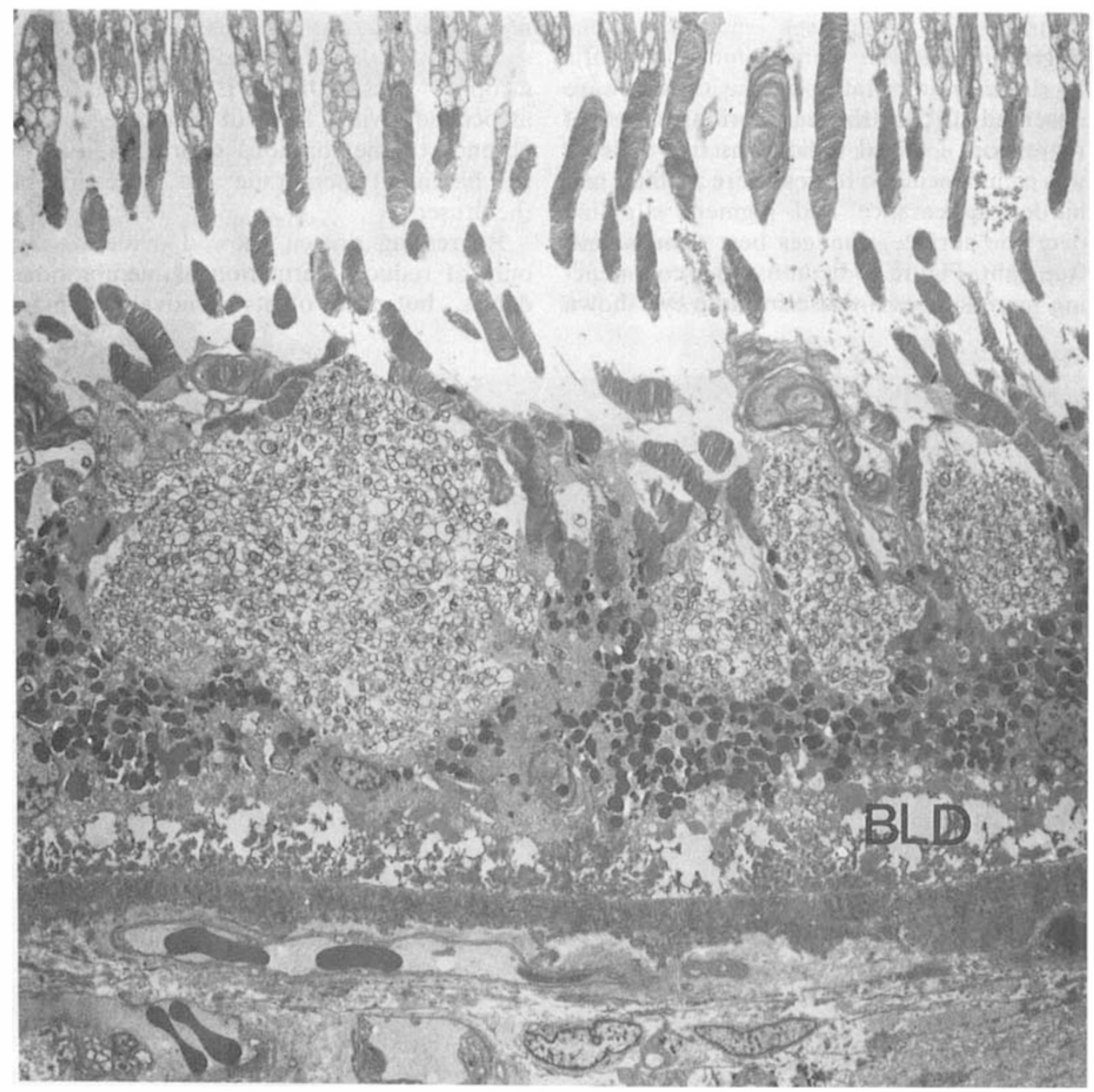

Fig. 18. Electron micrograph of an area shown in Fig 17. The photoreceptor outer segments terminate in focal collections of membranous debris which are partly surrounded by inward extensions of the RPE. Bush-like BLD and spaces containing sparse membranes lie under RPE. x1572 
findings in the fellow eye. The risk of choroidal neovascularisation appeared to relate more directly to the size of the area.

Table II highlights the tendency for atrophy to lie outside the fovea. When



Fig. 19. Left eye of a 91-yr-old woman, photographed nine months before death, showing the late stage of geographic atrophy associated with choroidal atrophy. Choroidal veins retain wide blood column but arteries are sheathed or reduced to white lines. Sections were cut horizontally through centre of area. atrophy first encroached into the fovea it was already approaching that of the disc in total area (approximately $1.75 \mathrm{~mm}^{2}$ ). In eyes with one-third or less of the fovea affected, involvement of the fovea remained less than that of the parafovea (foveal: parafoveal ratio less than unity). With each additional third of foveal involvement the size of the GA increased considerably but most of the enlargement occurred outside the fovea. However, the lesions were often asymmetrically located leading to relative sparing of the parafovea on the opposite side and a ratio greater than unity. A small part of the fovea tended to survive a long time in such that eyes with $100 \%$ involvement the area of atrophy averaged $13.5 \mathrm{~mm}^{2}$, or more than seven times that of the disc.

Table II also indicates the most commonly recorded visual acuities but there was a wide range within in each group, reflecting the variable state of the retina beneath fixation. Visual acuity was a poor guide to the extent of atrophy and an even poorer indication of the functional handicap, many patients with good visual acuity being unable to scan a line of print. Fixation often became unsteady as atrophy approached the centre. Some patients continued to fix on a surviving island

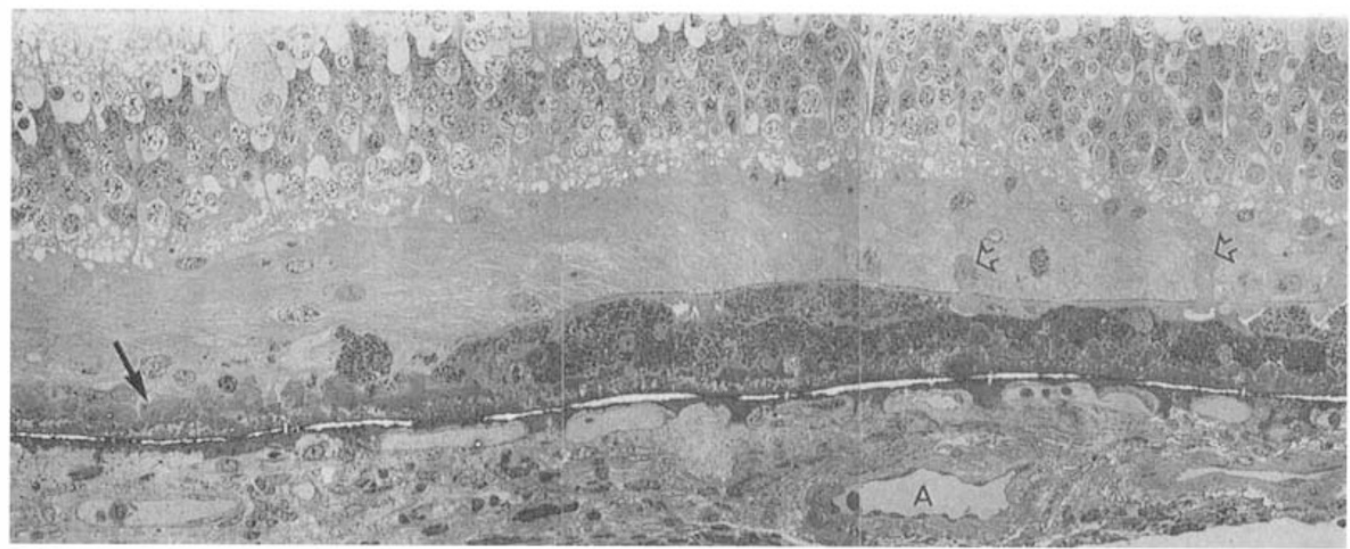

Fig. 20. Temporal edge of atrophic area shown in Fig. 19. The termination of the RPE is characterised by a double layer of cells, an inner necrotic layer lying on umbrella-shaped hyperpigmented cells. Apart from two surviving cones (arrowheads) photoreceptors have disappeared over these RPE cells. Absence of photoreceptors here may account for fixation moving some distance from edge. Flocculent $B L D$ is prominent under the RPE and continues into the area of atrophy at left (arrow). Here choriocapillaris disappears and intercapillary pillars of Bruch's membrane are eroded. Note choroidal artery $(A)$ retains wide lumen. Electronlucent spaces in Bruch's membrane were presumably caused by mineralisation. $x 472$ 
Table II. Extent of geographic atrophy in survey eye of 208 patients at time of diagnosis. Patients grouped according to percentage of fovea involved

\begin{tabular}{lccccc}
\hline $\begin{array}{l}\text { \% Fovea } \\
\text { affected }\end{array}$ & $\begin{array}{c}\text { No. of } \\
\text { patients }\end{array}$ & Av. age & Median V.A. & $\begin{array}{c}\text { Av. Area }\left(\mathrm{mm}^{2}\right) \\
\text { of atrophy }\end{array}$ & $\begin{array}{c}\text { Ratio \% Fovea } \\
\text { \% parafovea }\end{array}$ \\
\hline$<10$ & 33 & 72.4 & $6 / 9$ & 1.5 & 0.5 \\
$10-32$ & 54 & 74.9 & $6 / 12$ & 2.8 & 0.9 \\
$33-66$ & 53 & 76.3 & $6 / 18$ & 4.3 & 1.1 \\
$67-99$ & 46 & 75.6 & $6 / 60$ & 7.8 & 1.1 \\
100 & 22 & 80.7 & C.F. & 13.5 & 1.1 \\
\hline
\end{tabular}



Fig. 21. Termination of RPE and external limiting membrane (ELM) in same eye. Flocculent, multilaminar appearance of $B L D$ suggests formation in successive waves as the base of the RPE becomes increasingly separated from its basement membrane. RPE is filled with membrane-bound bodies containing melanolipofuscin granules embedded in grey matrix. Necrotic pigment epithelial cells are being eliminated. $x 2,240$ 


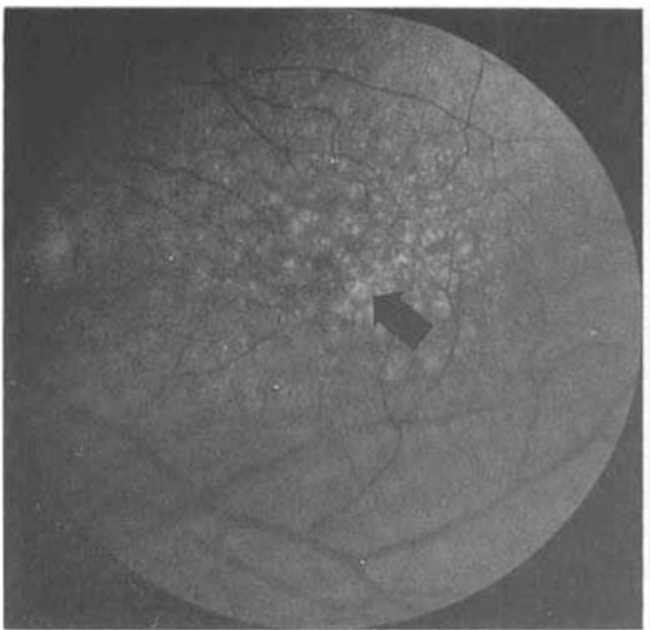

Fig. 22. Patient illustrating drusen-related atrophy sparing fixation. A 58-year-old woman with semisolid drusen made up of clusters of smaller hard deposits. Drusen are most prominent on temporal side of fovea. Arrow points to one cluster where drusen are whitening with pigment stippling over the surface, signs of early regression. A few small drusen lie close to fixation but central fovea is relatively spared and vision was $6 / 5 p$.

within the area of atrophy but found difficulty in maintaining fixation. Central fixation was not completely lost until atrophy occupied an average of $84.6 \%$ of the fovea. This occurred in the survey eye in 69 patients at an average age of 78.3 years and subsequently also in the fellow eye in 17 patients at an average age of 80.5 years, developing about five years earlier in the drusen-related group compared to the primary atrophy group.

\section{Fellow Eye}

Table III summarises the macular findings in the fellow eye at the time the patient was entered into the survey.

AMD (30 eyes) referred to eyes at an earlier stage of degeneration, often exhibiting incipient atrophy or even small patches of atrophy. GA qualifying for inclusion in the survey was bilateral in just over half the patients (111 eyes), being more than twice as common as evidence of choroidal neovascularisation in the fellow eye. There was a further tendency to symmetry in that the



Fig. 23. Fluorescein angiogram of same patient at age 66 showing atrophy in the distribution of the previous drusen. Stippling inside the atrophic patches represents surviving hyperpigmented RPE cells. The atrophy totals $8.1 \mathrm{~mm}^{2}$ and occupies $45 \%$ of the fovea and $52 \%$ of the parafovea. Smaller patches encircle fixation but vision remained 6/9.

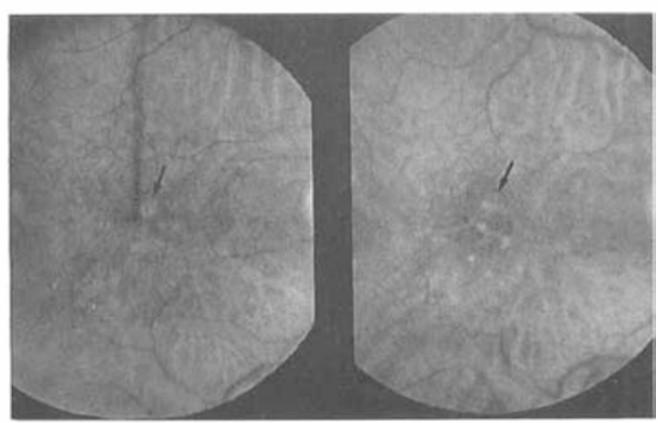

Fig. 24. A patient at age 79 (left) and 80 (right), showing early regression of drusen. A small patch of atrophy developed adjacent to fixation and slowly enlarged (arrows), other drusen also becoming whiter and harder. Sinuous pattern of shallow soft drusen is seen in upper part of fundus. Vision was 6/24. Cataract precluding further photography, patient dying at age 84. Sections were cut vertically through the fovea.

average area of atrophy in the fellow eye was only $20.5 \%$ smaller than that in the survey eye.

Evidence of prior choroidal neovascularisation was noted in approximately one-quarter of fellow eyes (54 eyes). The interval shown in Table III indicates how many 


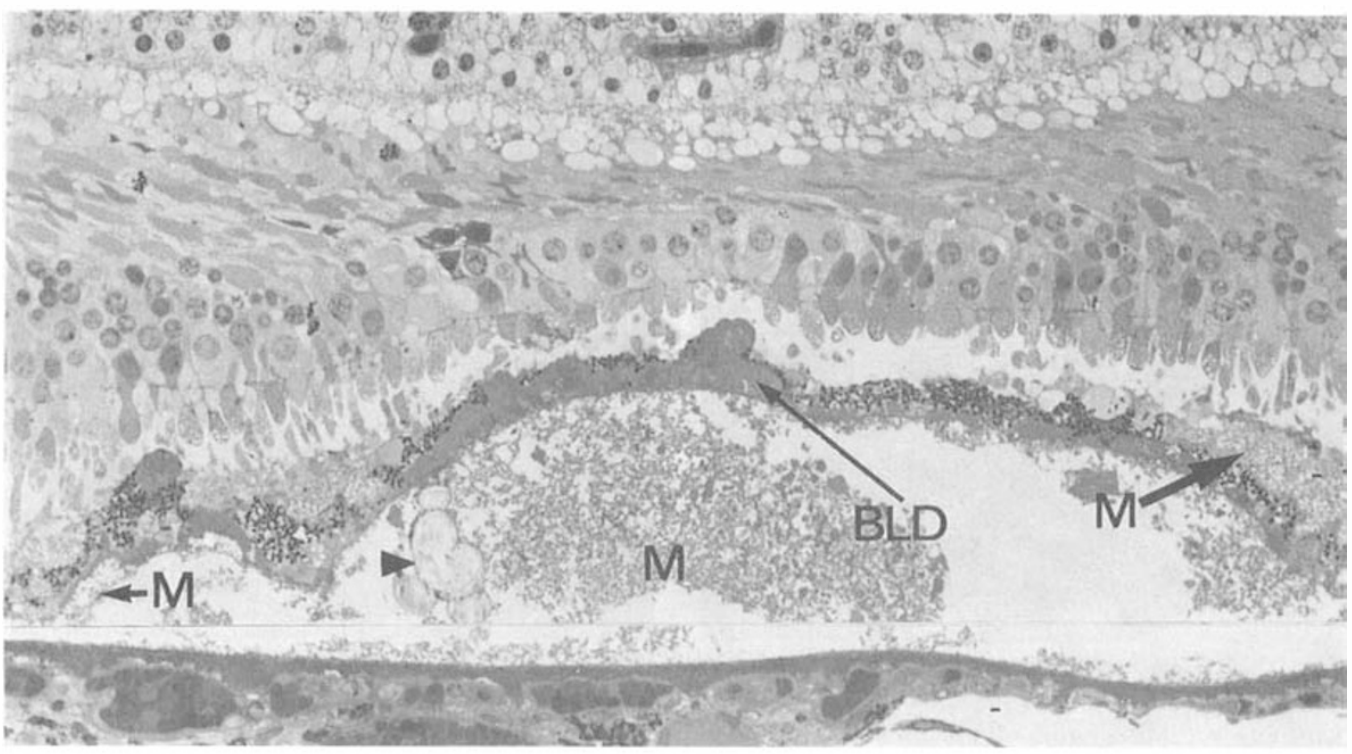

Fig. 25. Commencing regression of a soft druse from eye shown in Fig. 24. Confluence with smaller druse at left results in combined width of $310 \mu$. Contents are partly lost but appear to consist mainly of membranes with some amorphous material and patch of calcification (arrowhead). Over the apex the outer nuclear layer is reduced to two rows. External limiting membrane is bowed inwards but still present. Photoreceptor inner segments are stunted and reduced in number, outer segments are absent. RPE forms a continuous but markedly attenuated layer overlying a thick layer of flocculent BLD which presents a nodular internal surface. Membranus debris $(M)$ is seen in three locations: in the subretinal space at right; between the RPE and its basement membrane over the smaller druse at left; and inside the druse at centre. Methylene blue and basic fuchsin. $x 320$.

Table III. Macular findings in fellow eye of 208 patients. Patients grouped according to percentage of fovea involved by geographic atrophy in survey eye at time of diagnosis

\begin{tabular}{|c|c|c|c|c|c|c|c|c|c|}
\hline \multirow[t]{2}{*}{$\begin{array}{l}\text { SURVEY EYE } \\
\% \text { Fovea } \\
\text { affected }\end{array}$} & \multirow[t]{2}{*}{$A M D$} & \multicolumn{5}{|c|}{$\begin{array}{c}\text { FELLOW EYE } \\
\text { Geographic Atrophy (111 eyes) } \\
\% \text { fovea affected }\end{array}$} & \multicolumn{2}{|c|}{$\begin{array}{c}\text { Disciform } \\
\text { response }\end{array}$} & \multirow{2}{*}{$\begin{array}{c}\text { Other } \\
\text { diagnosis }\end{array}$} \\
\hline & & $<10$ & $10-32$ & $33-66$ & $67-99$ & 100 & no. & interval $(M)$ & \\
\hline$<10$ & 7 & 10 & 1 & 0 & 0 & 0 & 13 & 17.5 & 4 \\
\hline$<33$ & 12 & 8 & 11 & 0 & 0 & 0 & 19 & 14.9 & 3 \\
\hline $33-66$ & 9 & 4 & 15 & 8 & 0 & 0 & 12 & 39.5 & 3 \\
\hline $67-99$ & 1 & 1 & 11 & 10 & 14 & 0 & 9 & 58.9 & 1 \\
\hline 100 & 1 & 0 & 2 & 4 & 2 & 10 & 1 & 60.0 & 2 \\
\hline Total & 30 & 23 & 40 & 22 & 16 & 10 & 54 & & 13 \\
\hline
\end{tabular}

months earlier the patient thought that this had occurred. This interval was probably an underestimate in most cases, but the smaller the area of atrophy in the survey eye, the more recently the neovascular response had occurred in the fellow eye.

\section{Follow up}

Progress of atrophy was documented by photography in 61 patients for an average period of 28.9 months (Table IV). Both the size of the area and the percentage of foveal involvement increased annually by more than 




Fig. 26. Druse from same eye, showing more advanced regression. Over the apex a few necrotic retinal pigment cells lie on the flocculent BLD but the outer nuclear layer and photoreceptors have disappeared. External limiting membrane moves progressively down the slopes of the druse (arrows) and defines the limits of atrophy. Methylene blue and basic fuchsin. x320

Table IV. Progress of atrophy in survey eye of 61 patients. (Average follow up period 28.9 months)

\begin{tabular}{|c|c|c|c|}
\hline $\begin{array}{l}\% \text { Fovea } \\
\text { affected }\end{array}$ & $\begin{array}{c}\text { No. of } \\
\text { patients }\end{array}$ & $\begin{array}{c}\text { Av annual } \\
\% \text { increase } \\
\text { in area }\end{array}$ & $\begin{array}{c}\text { Av annual } \\
\text { increase in } \% \\
\text { of foveal } \\
\text { involvement }\end{array}$ \\
\hline$<33$ & 34 & 121.8 & 126.4 \\
\hline $33-66$ & 10 & 47.1 & 22.1 \\
\hline $67-100$ & 13 & 24.9 & 5.3 \\
\hline 100 & 4 & 14.9 & \\
\hline
\end{tabular}

$100 \%$ at first, slowing rapidly as GA involved more of the degenerate retina affected by incipient atrophy.

\section{Subsequent choroidal neovascularisation}

Seven patients developed new vessels in the survey eye during this period. Only one had advanced atrophy, the other six having atrophy that averaged $1.9 \mathrm{~mm}^{2}$ in area or little larger than that of the disc and occupying



Fig. 27. Fundus of an 83-year-old man who developed drusen-related atrophy around the fovea over five years. The drusen underwent regression, becoming whiter with irregular outlines and foci of mineralisation. Vision was 6/12. The patient died 15 months later. 




Fig. 28. Semi-thin section showing one of the calcified drusen located in the upper part of the fovea of the eye shown in Fig. 27. The druse is covered by flocculent BLD (short arrow) and contains extensive mineral deposits embedded in collagen. Small vessel (long arrow) passes through gap in Bruch's membrane. Small vessel (long arrow) passes through gap in Bruch's membrane beneath druse. Avascular fibrous tissue ( $F$ ) lies on Bruch's membrane. Methylene blue and basic fuchsin. x320

only $16.3 \%$ of the fovea. The new vessels in these seven patients developed soon after entry into the survey, after an average follow up period of only 6.2 months. Four of these patients had also developed new vessels in the fellow eye within the previous 12 months. Only one patient developed new vessels in the fellow eye after entry into the survey (although 54 had done so beforehand).

\section{Discussion}

The Framingham study designated eyes without evidence of choroidal neovascularisation as the 'atrophic' form of AMD. ${ }^{3}$ Since this would include eyes manifesting only drusen and pigment change which might still be predisposed to the exudative form, the description 'atrophic' should be limited to those eyes actually demonstrating atrophy. A similar picture can result from other disorders damaging the RPE and GA remains to be clarified as a separate entity when representing the end stage of AMD.

An earlier clinicopathological study ${ }^{5}$ of ageing and degeneration at the macula traced the histological changes culminating in GA and this is revised in the light of the ultrastructural findings (Fig.29). The original classification is retained, the eyes being grouped according to the appearance of the BLD under the macula. The deposit is absent in group I, appearing in a patchy distribution in group II. Groups III and IVa reflect the onset and progress of macular degeneration, the deposit first becoming continuous and then thickening. In incipient atrophy and towards the junctional zone (group IVb) the BLD mainly comprises the later, flocculent form which can be traced into the area of atrophy, group V.

Subretinal neovascularisation is first demonstrated in group IVa and is accompanied by a low-grade chronic inflammatory reaction. If neovascularisation does not develop or remains limited in extent, the natural end-result is geographic atrophy. Group VI, or disciform degeneration, is not represented here. 




Fig. 29. Diagram showing changes found under macula during evolution of geographic atrophy. Groups I and II represent normal ageing, III and IV a the onset and progress of age-related degeneration. IVb indicates the changes immediately preceding geographic atrophy $(V)$. Diagram may also be inter preted to show changes surrounding an area of geographic atrophy.

Three manifestations of failure of $R P E$ are represented:

1) Accumulation of lipofuscin leading cellular to hypertrophy and later to elimination of spent cells or portions of cells.

2) Formation of two types of basal laminar deposit.

(a) Early: a pale-staining, striated or bush-like form.

(b) Late: a hyalinised, flocculent form.

3) Discharge of cellular debris.

(a) Early: cytoplasmic material causing thickening of Bruch's membrane and also found in small hard drusen.

(b) Late: coiled membranous debris found in three locations-external to the basement membrane of the retinal pigment epithelium as a continuous layer; internal to the basement membrane as focal mounds; internal to the retinal pigment cells forming localised collections in the subretinal space.

Life-cycle of drusen is shown:

1) In the first three groups the drusen shown are the small hard, hyalinised variety.

2) In group IV the admixture of membranous debris causes a hyalinised druse to break down. This mixed or semi-solid druse is larger and no longer hemispherical.

3) Focal accentuations of the layer of membranous debris external to the basement membrane may form soft drusen de novo.

4) In incipient atrophy and at the junctional zone the drusen commence to regress. Before being shed the RPE elaborates flocculent BLD and mineralization may develop in the druse. In the area of atrophy the drusen have become replaced by cell processes, collagen fibres and calcium.

Evolution of Geographic Atrophy: Pathological Changes.

\section{Photoreceptors.}

With age a dropout of foveal cones occurs, ${ }^{11}$ followed by an increase in diameter of the remaining inner segments. Loss of photoreceptors becomes more apparent in groups
III and IV and appears to be accompanied by a failure of phagocytosis of outer segments. In the junctional zone the few surviving photoreceptors are grossly abnormal and disappear pari passu with the RPE.

Applying the arguments used by Runge et $\mathrm{al}^{12}$ to determine in which tissue the primary 
defect occurred, the fallout of photoreceptors appeared to be secondary to changes in and beneath the RPE which were noted at a much earlier stage. Alteration in the photoreceptors was not observed independently of changes in the RPE and the reduction in photoreceptor nuclei parallelled loss of RPE. The possibility remains, however, that the initial damage may have occurred to the photoreceptor outer segments, such that after phagocytosis by the RPE the lysosomal enzymes may fail to 'recognise' and degrade the abnormal molecules ${ }^{13}$ with the consequent accumulation of lipofuscin.

\section{Retinal Pigment Epithelium}

The weight of opinion ${ }^{5,13,14}$ supports Hogan's ${ }^{15}$ view that gradual failure of the RPE is the principal cause of AMD since this layer of cells must continue to engulf spent photoreceptor tips for life. The increase in lipofuscin causes a detectable enlargement of the cells during normal ageing. As the cytoplasmic space available to the organelles is reduced, cell metabolism is affected. ${ }^{13,16,17}$ This becomes evident at the base of the cells where a reduction in the basal infoldings is associated with deposition of basement membrane material and shedding of membranous debris, such that the base of the cells becomes increasingly separated from its basement membrane.

Experiments indicate there is no feedback control and ingestion continues until cell death occurs. ${ }^{18}$ The lipofuscin may be eliminated in necrotic cells, in fragments of cells or as free granules. This occurs both into the subretinal space and subpigment epithelial space, most of the lipofuscin then probably being taken up by adjacent pigment cells which therefore become increasingly pigmented and enlarged. As these in turn are shed, the remaining cells migrate and increase in surface area in an attempt to maintain continuity and when this process can no longer compensate for cell loss, atrophy results.

Attenuation of the retinal pigment epithelium is therefore most pronounced adjacent to the clumps or lines of hyperpigmentation and is the prelude to the development of patches of atrophy. ${ }^{6}$ This mechanism for the removal of dead cells appears to be common to a variety of conditions in which the fundus shows pigment clumping or pigment patterns. These cells shed into the subretinal space retain epithelial characteristics which distinguish them from macrophages. ${ }^{19}$ Likewise the pigment-laden cells found under the basement membrane of the RPE are also probably spent RPE cells.

\section{Bruch's membrane}

The thickening of Bruch's membrane with age is due mainly to the accumulation of coated membrane-bound bodies. Most rupture to release their content of vesicular and granular material, as well as fragments of the coated membrane. ${ }^{20-22}$ Hogan ${ }^{15}$ originally proposed that they might be incompletely digested phagosomes but the failure to demonstrate lysosomal activity implies the RPE does not normally extrude derivatives of the phagolysosomal system..$^{21}$

It has been suggested that these bodies are derived by the evagination and separation of a small portion of pigment epithelial cytoplasm. ${ }^{22,23}$ This process has been likened to apoptosis ${ }^{23-25}$ which in this sense implies cell rejuvenation by the elimination of damaged cell membrane and organelles. However, the present study confirms the finding of FeeneyBurns et $\mathrm{a}^{21}$ that the physical separation of bodies from the RPE cannot be demonstrated until degeneration of the cells is advanced. Since this material is found as early as the second decade it appears to represent a normal but unknown mechanism by which the RPE discards unwanted material.

Histologically these changes are not detected until the fifth decade when patchy thickening and hyalinisation of Bruch's membrane appear (group I). When maximally developed these changes extend down the intercapillary pillars to the level of the outer surface of the choriocapillaris and may even surround the capillaries. In group IVa this degree of hyalinisation was observed to extend over three disc diameters, ${ }^{5}$ corresponding approximately to the area of incipient atrophy in these eyes. However, this accumulation in Bruch's membrane appears to be the result rather than the cause of degeneration of the RPE. In long standing 
GA the membrane becomes thinner again and once the choriocapillaris is obliterated the intercapillary pillars become eroded by cellular activity.

\section{Basal laminar deposit - early form}

Histologically the early form of the BLD appears as a pale-staining layer with faint vertical striations. On electron microscopy it is homogeneous basement membrane material which can also appear fibrillar and later banded. It spreads inwards from the basement membrane in a palisading or bush-like pattern $^{26}$ and therefore lies between the plasma membrane and the basement membrane, unlike typical drusen which form external to the basement membrane.

This early type BLD is first detected in the seventh decade during normal ageing. It develops over thickened or basophilic segments of Bruch's membrane, widened intercapillary pillars or small drusen ${ }^{5}$, suggesting it may be a response to altered filtration at these sites. As degeneration develops it forms a continuous layer which then thickens, but with more severe degeneration the BLD elaborated is mostly of the later form.

\section{Membranous debris.}

The debris composed of coiled membrane fragments appears in normal aged eyes about the same time as the BLD, giving it a vacuolated appearance. ${ }^{27}$ By conventional histological techniques the collections of membranes are only evident as small rounded spaces in the BLD and at the time that the histopathological implications of the BLD were originally described ${ }^{5}$, the presence of this material was not recognised.

These fragments resemble the coiled phospholipid membranes released by the cells of the central nervous system and appear to be extruded from the basal surfaces of the RPE, analogous to the shedding of discs by the photoreceptors. The membranes form layers and then mounds internal to the basement membrane. As the mounds enlarge and fuse together, the RPE shows progressive derangement and cell fall-out. Where the debris is discharged external to the basement membrane it results in the softening of drusen.
Membranous debris was therefore found in three situations--internal to the RPE in the subretinal space; between the RPE and its basement membrane; and external to the basement membrane--but irrespective of its location it was always dependent on the presence of photoreceptors. It therefore reduces in quantity again where photoreceptors are beginning to fall out in the transitional zones and over regressing drusen, before disappearing altogether once atrophy develops.

\section{Basal laminar deposit - late form}

In group IVa another form of BLD appears. Histologically it forms a deeply staining hyalinised layer on the internal surface of the earlier form. On electron microscopy this late form anchors the base of the cells to Bruch's membrane for a time but then becomes uplifted with the attenuated RPE over the membranous mounds. It therefore lies at different levels representing successive waves of formation according to the position of the base of the cells at the time and this gives it a flocculent or cumuliform appearance. It indicates a more severely stressed RPE, being maximally developed in the junctional zones and over regressing drusen. It then continues into the area of atrophy together with a discontinuous layer of the early form.

\section{Choroid}

Age-related macular degeneration has of ten been ascribed to narrowing of the choriocapillaris, the area occupied by patent capillaries falling from $71 \%$ in group 1 to $44 \%$ in group $\mathrm{IVa},{ }^{28}$ before petering out in group V. However, in both clinical situations and in histological preparations the choroidal capillaries persist for a time after loss of the retinal pigment epithelium. ${ }^{29}$ Green and $\mathrm{Key}^{2}$ pointed out that the comparative sparing of the inner nuclear layer indicates the disease is not based on choroidal insufficiency and other observers also regard the vascular changes as secondary to the reduced requirement of the outer retina. $5,14,26$ The fact that patches of pigment epithelial atrophy commonly corespond in size to choriocapillary lobules also raises the question of whether the process might begin in 
the choroid. 30,31 However, these discrete patches probably formed over and around larger drusen and happened to reach a lobular size before coalescing. This view does not deny the possibility that the initial distribution of drusen may bear some relationship to the choriocapillaris, since small drusen have been noted to occur preferentially over intercapillary pillars while clusters conform to choriocapillary lobules. ${ }^{32}$

Long standing GA followed by choroidal atrophy causing white sheathing of the exposed choroidal vessels was noted in 36 patients and was always bilateral when GA was bilateral. It was most evident in advanced cases when the area in the first eye averaged $11.1 \mathrm{~mm}^{2}$ and had involved $81.3 \%$ of the fovea. However, since choroidal atrophy is also a function of normal ageing the picture develops more rapidlylder patients, the average age in this series being 80.9 years.

\section{Dot-like drusen}

Red-free photographs often revealed small round dots in the surrounding retina, $25-50 \mu$ in size. They were hyperfluorescent in the later phases of the fluorescein angiogram. They could not be correlated with small hyalinised drusen in the pathological specimens, nor was lipoidal degeneration of RPE cells observed with sufficient frequency to account for their presence. One explanation for these dot-like drusen is the nodular excrescences on the internal surface of the flocculent BLD which are of a similar size and morphology to the earliest hard drusen. However, these nodules were not evenly distributed, being most evident over regressing drusen. A more likely cause is the rounded mounds of membranous debris.

\section{Chronic inflammatory cells}

The retinal pigment epithelium itself is capable of phagocytosing the debris released as a result of the normal cell deletion which occurs with age. However, when the amount of debris exceeds the phagocytic capacity of this tissue it attracts macrophages and giant cells ${ }^{33}$ which may in turn be the forerunner of new vessel ingrowth. Since the junction zone is the area from which the greatest amount of debris has to be removed, the cellular activity is maximal here and this is also where new vessels are found in eyes with GA. ${ }^{5}$

Fibroblasts and chronic inflammatory cells are also found in relation to the outer surface of Bruch's membrane, especially in the vicinity of breaks in Bruch's membrane. Choroidal neovascularisation in group IVa may be accompanied by giant cells and macrophages and appears to be part of a chronic inflammatory reaction in response to the build up of debris.

\section{Drusen}

In so far as drusen are an exaggerated manifestation of RPE disfunction, drusen-related atrophy would be expected to be a more severe form of primary age-related atrophy. Gass $^{1}$ observed that most cases of GA follow the fading of drusen and this study confirmed that these eyes lose fixation earlier, the pattern of atrophy being determined by their type, number, and distribution.

Drusen have been divided on a histochemical basis into lipid and proteinaceous ${ }^{9}$ and on the clinicopathological findings into hard and soft, ${ }^{34}$ although two other categories that may be distinguished are a mixed or semisolid type and regressing drusen. Other terms, such as diffuse drusen ${ }^{35,36}$ or basal laminar drusen ${ }^{37}$ refer to material internal to the basement membrane.

Both hard and soft drusen appear to be derived from the RPE, their composition reflecting the state of the overlying cells at the time. The contents of early hard drusen resemble the material accumulating in Bruch's membrane and may likewise be found at an early age. They are the predominant type of druse found in the first three groups and the only type in Group I.

Hard drusen are well tolerated for many years but lead to a focal pigment disturbance and ultimately a localised patch of atrophy. Excessive numbers represent a recognisable pattern predisposing to GA at a younger age,$^{38}$ although is not clear if these represent a dystrophy which should not be included in a study of AMD. A positive family history was not obtained in this series.

Clusters of hard drusen are most common about a disc diameter from fixation but they 
may also be numerous further out, especially on the temporal side. Towards the equator they may be associated with a linear pigment pattern giving rise to the picture of reticular (honeycomb) degeneration of the pigment epithelium. Such eyes have a high association with geographic atrophy. ${ }^{39}$

The appearance of membranous debris is an age-related change. In some eyes this material remains as mounds internal to the basement membrane. In others it passes through the basement membrane, the admixture of membranous components causing the clusters of hard drusen to soften and form larger semisolid deposits. In this series a parafoveal belt of varying width, characterised by semisolid drusen or a microreticular pigment pattern or both, was the preferential site for the development and spread of GA which therefore mostly tended to spare fixation.

Choroidal neovascularisation also tends to develop outside the central rod-free area at the stage when semisolid drusen become most apparent, possibly in response to the same debris. Debris discharged external to the basement membrane may not only accelerate the progress of GA but also predispose to new vessel formation.

Less commonly GA commences within the fovea. Here, where clusters of hard drusen are less common, a build up of membranes appears to cause the formation of soft drusen de novo. Soft drusen evolve more rapidly, an increase in size and confluence often heralding a patch of atrophy. However, in the present study confluent soft drusen or drusen RPE detachments appeared to be an uncommon forerunner of GA.

\section{Spread of atrophy}

Both primary atrophy and drusen-related atrophy tended to spread around the central fovea, the former in a horseshoe-like fashion $^{30}$ and the latter as separate patches which enlarged and coalesced. The spread of GA is therefore different to that of choroidal neovascular membranes which may likewise commence outside the rod-free area but have a propensity to spread into fixation. The degree of incipient atrophy determines the rapidity and direction of spread of GA and once has accupied all the retina affected by incipient atrophy, progress is slowed.

The reason atrophy tends to skirt fixation may be determined by the topographical distribution of lipofuscin, since this increases at the posterior pole but shows a dip at the fovea. ${ }^{17}$ This parallels the distribution of rods in the human retina and probably reflects the high turnover of rod discs, whereas the cone system may take nine months to a year to renew. ${ }^{40}$

Where the RPE had totally disappeared photoreceptors were always absent and no function was possible, but within an area of atrophy it was not uncommon to find a whorl of persisting photoreceptors converging on a cluster of degenerating pigment cells. Clinically an area of atrophy often showed some residual pigment mottling and some patients continued to fix on larger surviving islands within the area of atrophy. These islands underscore the greater resistance of the central fovea, a feature which characterises all the bull's-eye maculopathies.

\section{Functional impact}

Clearly the size of the affected area does not reflect visual acuity, nor does visual acuity relate to functional handicap. By the time loss of fixation did occur atrophy had in many eyes already involved most of the fovea and the visual acuity recorded varied depending on the patient's ability to find a surviving island of retina within the atrophic area or the least affected retina outside the area. ${ }^{41}$

A macular threshold strategy on an autoperimeter confirmed that the absolute scotoma was surrounded by a relative scotoma on which patients may continue to fix and a patient may be directed to using a more suitable area of retina by visual retraining. ${ }^{42}$ Several patients preferred to fix some distance from the edge of the atrophy and possibly this was due to the absence of photoreceptors over the retinal pigment cells around the edge and the even wider zone of impaired phagocytosis found in this study.

\section{Follow up}

Maguire and Vine ${ }^{30}$ found that the average interval from onset to legal blindness was nine years. In this present study the spread of 
atrophy and the percentage of foveal involvement increased at an annual rate of over $100 \%$ at first, slowing abruptly as more of the degenerate retina became involved. As indicated in Table IV, a hypothetical patient presenting with $10 \%$ foveal involvement and $6 / 6$ vision might take five years before $80 \%$ of the fovea is involved, at which stage fixation is generally affected.

It is to be emphasised that such generalisations are valueless as prognostic indicators in an individual case, but in this aged population the question of cataract extraction often arises. Since spread does not occur into normal retina the survival of the central retina may be estimated by noting the extent and degree of incipient atrophy, while pointing out that an improvement in visual acuity may not translate into reading ability.

\section{Choroidal neovascularisation}

New vessel ingrowth is dependent upon a viable RPE and can only occur outside the area of atrophy, spreading in the plane created by the layer of membranous debris external to the basement membrane. Atrophy therefore limits the neovascular response which may even remain subclinical. In a clinicopathological study of 46 eyes with a clinical diagnosis of geographic atrophy ${ }^{5}, 15$ were found to have unsuspected new vessels. Choroidal neovascularisation is therefore more frequent than clinical studies suggest but one pointer to their presence was that the other eye had earlier developed a disciform response.

In the present series, seven patients developed new vessels during follow up. In six the GA had been about the size of the disc and such an eye is therefore still at risk, especially if the other eye has recently developed new vessels. Only one patient had advanced atrophy and as the area of GA enlarged in the first eye, the risk of developing overt choroidal neovascularisation appeared to decline in both eyes. As exemplified by the patient illustrated in Figs.3-6, the propensity for GA to spare fixation means an eye can retain central vision for up to eight years longer than the fellow eye with choroidal neovascularization. Since the spread of GA into all the retina affected by incipient atrophy also appears to offer some protection from this complication, this pattern of evolution may become a model for more aggressive ablation during treatment of choroidal neovascular membranes.

We are grateful to Dr. G. Carter, Medical Superintendent of Lidcombe Hospital, for permission to publish this paper. We also wish to acknowledge the support of the Gerontology Foundation of Australia.

Thanks are also due to Dr. M. Dickson, Department of Electron Microscopy, Universtity of New South Wales, for the provision of electron microscopic facilities and to Miss C. Espinoza for technical assistance.

\section{References}

${ }^{1}$ Gass JDM: Drusen and disciform macular detachment and degeneration. Arch Ophthalmol 1973; 90: 206-17.

${ }^{2}$ Green WR, Key SN III: Senile macular degeneration: a histopathologic study. Trans Am Ophthalmol Soc 1977; 75: 180-254.

${ }^{3}$ Leibowitz HM, Krueger DE, Maunder LR et al: The Framingham Eye Study Monograph: VI. Macular Degeneration. Surv Ophthalmol 1980; 24 (suppl): 428-57.

${ }^{4}$ Hyman LG, Lilienfeld AM, Ferris FL III, Fine SL: Senile macular degeneration: A case-control study. Am J Epidemiol 1983; 118: 213-27.

${ }^{5}$ Sarks SH: Ageing and degeneration in the macular region: a clinico-pathological study. Br J Ophthalmol 1976; 60: 324-41.

${ }^{6}$ Keno DD, Green WR: Retinal pigment epithelial window defect. Arch Ophthalmol 1978; 96: 854-6.

${ }^{7}$ Macular Photocoagulation Study: Manual of Procedures. Baltimore, Maryland 1986, p.148.

${ }^{8}$ Sarks SH, van Driel D, Maxwell L, Killingsworth M. Softening of drusen and subretinal neovascularisation. Trans Ophthalmol Soc UK 1980; 100: 414-22.

${ }^{9}$ Bird AC, Marshall J: Retinal pigment epithelial detachments in the elderly. Trans Ophthalmol Soc UK 1986; 105: 674-82.

${ }^{10}$ Burgess DB, Olk RJ, Uniat LM: Macular disease resembling adult foveomacular vitelliform dystrophy in older adults. Ophthalmology 1987; 94: 362-6.

${ }^{11}$ Grindle CFJ, Marshall J: Ageing changes in Bruch's membrane and their functional implications. Trans Ophthalmol Soc UK 1978; 98: 172-5.

${ }^{12}$ Runge P, Calver D, Marshall J, Taylor D: Histopathology of mitochondrial cytopathy and 
the Lawrence-Moon-Biedl syndrome. $\mathrm{Br} J$ Ophthalmol 1986; 70: 782-96.

13 Young RW: Pathophysiology of age-related macular degeneration. Surv Ophthalmol 1987; 31: 291-306.

${ }^{14}$ Marshall J, Laties A: The special pathology of the aging macula. In Retinal Degeneration: Experimental and Clinical Studies, Alan R Liss Inc 1985, 389-400.

${ }^{15}$ Hogan MJ: Role of the retinal pigment epithelium in macular disease. Trans Amer Acad Ophthalmol Otolaryngol 1972; 76: 6480.

${ }^{16}$ Feeney-Burns L, Hilderbrand ES, Eldridge S. Aging human RPE: morphometric analysis of macular, equatorial and peripheral cells. Invest Ophthalmol Vis Sci 1984; 25: 195-200.

17 Wing GL, Blanchard GC, Weiter JJ: The topography and age relationship of lipofuscin concentration in the retinal pigment epithelium. Invest Ophthalmol Vis Sci 1978; 17: 601-7.

${ }^{18}$ Boulton M, Marshall J: Effects of increasing numbers of phagocytic inclusions on human retinal pigment epithelial cells in culture: a model for aging. $\mathrm{Br} J$ Ophthalmol 1986; 70: 808-15.

${ }^{19}$ Ishikawa Y, Momoeda S, Yoshitomi F: Origin of macrophages in photocoagulated rabbit retina. Jpn J Ophthalmol 1983; 27: 138-48.

${ }^{20}$ Killingsworth MC: Age-related components of Bruch's membrane in the human eye. Graefes Arch Clin Exp Ophthalmol 1987; 225: 406-12.

${ }^{21}$ Feeney-Burns L, Gao Chun Lan, Tidwell M: Lysosomal enzyme cytochemistry of human RPE, Bruch's membrane and drusen. Invest Ophthalmol Vis Sci 1987; 28: 1138-47.

${ }^{22}$ Feeney-Burns L, Ellersieck MR: Age-related changes in the ultrastructure of Bruch's membrane. Am J Ophthalmol 1985; 100: 686-97.

${ }^{23}$ Ishibashi T, Sorgente N, Patterson R, Ryan SJ: Aging changes in Bruch's membrane of monkeys: an electron microscopic study. Ophthalmologica Basel 1986; 192: 179-90.

${ }^{24}$ Burns RP, Feeney-Burns L: Clinico-morphologic correlations of drusen of Bruch's membrane Trans Am Ophthalmol Soc 1980; 78: $206-25$.

${ }^{25}$ Kerr JFR, Wyllie AH, Currie AR: Apoptosis: a basic biological phenomenon with wide-ranging implication in tissue kinetics. $\mathrm{Br} J$ Cancer 1972; 26: 239-57.

${ }^{26}$ Löffler KU, Lee WR: Basal linear deposit in the human macula. Graefe's Arch Clin Exp Ophthalmol 1986; 224: 493-501.

${ }^{27}$ Fine BS, Yanoff M: Ocular Histology: A Text and Atlas, 2nd ed, p47. Hagerstown 1979, Harper and Row.

${ }^{28}$ Sarks SH: Changes in the region of the choriocapillaris in ageing and degeneration. XXIII Concilium Ophthalmol Kyoto. 1978, 228-238.

${ }^{29}$ Henkind P, Gartner S: The relationship between retinal pigment epithelium and the choriocapillaris. Trans Ophthalmol Soc UK 1983; 103: 444-7.

${ }^{30}$ Maguire P, Vine AK: Geographic atrophy of the retinal pigment epithelium. Am $J$ Ophthalmol 1986; 102: 621-5.

${ }^{31}$ Weiter J, Fine BS: A histologic study of regional choroidal dystrophy. Am J Ophthalmol 1977; 83: 741-50.

32 Tso MOM: Pathogenetic factors of aging macular degeneration. Ophthalmology 1985; 92: 628-35.

${ }^{33}$ Penfold PL, Killingsworth MC, Sarks SH: Senile macular degeneration: The involvement of giant cells in atrophy of the retinal pigment epithelium. Invest Ophthalmol Vis Sci 1986; 27: 364-71.

${ }^{34}$ Sarks SH: Drusen and their relationship to senile macular degeneration. Aust J Ophthalmol 1980; 8: 117-30.

${ }^{35}$ Kenyon KR, Maumenee AE, Ryan SJ, Whitmore PV, Green WR: Diffuse drusen and associated complications. Am J Ophthalmol 1985; 100: 119-28.

${ }^{36}$ Green WR, McDonnell PJ, Yeo JH: Pathological features of senile macular degeneration. Ophthalmology 1985; 92: 615-627.

${ }^{37}$ Gass JDM, Jallow S, Davis B: Adult vitelliform macular detachment occurring in patients with basal laminar drusen. Am J Ophthalmol 1985; 99: 445-59.

${ }^{38}$ Sarks SH: Drusen patterns predisposing to geographic atrophy of the retinal pigment epithelium. Aust J Ophthalmol 1982; 10: 91-7.

${ }^{39}$ Lewis H, Straatsma BR, Foos RY: Chorioretinal juncture. Multiple extramacular drusen. Ophthalmology 1986; 93: 1098-112.

${ }^{40}$ Foulds W: Factors influencing visual recovery in retinal detachment surgery. Trans Ophthalmol Soc UK 1980; 100: 72-7.

${ }^{41}$ Weiter JJ, Wing GL, Trempe CL, Mainster MA: Visual acuity related to retinal distance from the fovea in macular disease. Ann Ophthalmol 1986; 16: 174-6.

42 Harris MJ, Robins D, Dieter JM Jr, Fine SL, Guyton DL: Eccentric visual acuity in patients with macular disease. Ophthalmolgy 1985; 92: 1550-53. 